\title{
Simultaneous calibration of multiple hydrodynamic model parameters using satellite altimetry observations of water surface elevation in the Songhua River
}

\author{
Jiang, Liguang; Madsen, Henrik; Bauer-Gottwein, Peter
}

\section{Published in:}

Remote Sensing of Environment

Link to article, DOI:

10.1016/j.rse.2019.03.014

Publication date:

2019

Document Version

Peer reviewed version

Link back to DTU Orbit

Citation (APA):

Jiang, L., Madsen, H., \& Bauer-Gottwein, P. (2019). Simultaneous calibration of multiple hydrodynamic model parameters using satellite altimetry observations of water surface elevation in the Songhua River. Remote Sensing of Environment, 225, 229-247. https://doi.org/10.1016/j.rse.2019.03.014

\section{General rights}

Copyright and moral rights for the publications made accessible in the public portal are retained by the authors and/or other copyright owners and it is a condition of accessing publications that users recognise and abide by the legal requirements associated with these rights.

- Users may download and print one copy of any publication from the public portal for the purpose of private study or research.

- You may not further distribute the material or use it for any profit-making activity or commercial gain

- You may freely distribute the URL identifying the publication in the public portal 


\title{
Simultaneous Calibration of Multiple Hydrodynamic Model Parameters using Satellite Altimetry Observations of Water Surface Elevation in the Songhua River
}

\author{
Liguang Jiang ${ }^{1, *}$, Henrik Madsen ${ }^{2}$, and Peter Bauer-Gottwein ${ }^{1}$ \\ ${ }^{1}$ Department of Environmental Engineering, Technical University \\ of Denmark, 2800 Kgs. Lyngby, Denmark \\ ${ }^{2}$ DHI, Agern Allé 5, 2970 Hørsholm, Denmark \\ *Corresponding author: Liguang Jiang (1jia@env.dtu.dk)
}


1 Abstract

2 Hydrodynamic modeling is an essential tool to simulate water level for flood forecasting and risk

3 assessment. However, parameterization of hydrodynamic models is challenging due to poor

4 knowledge of bathymetry and lack of gauge data. In this study, we present an approach for

5 calibrating spatially distributed Strickler coefficient and river datum simultaneously by regularized

6 inversion. Calibration was carried out using altimetry derived observation of water surface

7 elevation in the Songhua River (China). Synthetic experiments show that spatial variability of

8 model parameters can be well constrained by geodetic altimetry, e.g., CryoSat-2 and SARAL, and

9 to a lesser extent by Envisat and Jason-1. However, Jason-2 can only recover some of the

10 parameters. We also find that a higher accuracy of observations does not proportionally decrease

11 parameter uncertainty for all cross sections. Instead, high spatial sampling density helps to identify

12 the spatial variability of parameters. Real-world calibrations indicate that CryoSat-2 by far

13 outperforms other altimeters in terms of parameter identification. We conclude that high spatial

14 resolution is more important than temporal resolution and observation accuracy for calibrating

15 parameters of large-scale river models. The findings demonstrate the added value of geodetic

16 satellite altimetry for inversion of spatially resolved parameter fields. This study is timely because

17 the upcoming Surface Water and Ocean Topography mission will significantly improve spatial and

18 temporal resolution of spaceborne observations of water surface elevation, and hydraulic models

19 need to be prepared for the uptake of these data.

\section{Keywords}

21 Satellite altimetry; CryoSat-2; hydrodynamic modeling; channel bathymetry; calibration; inversion;

22 Songhua River 


\section{Introduction}

Climate change and human activities have altered the hydrological cycle and led to increased frequency of extreme events, such as droughts and floods (Blair and Buytaert, 2016; Madsen et al., 2014; Mann et al., 2017). Hydrodynamic (HD) modeling is of paramount importance in flood forecasting and management systems (Hostache et al., 2009). One of the key steps in HD modeling is calibration where model parameters (e.g. hydraulic resistance) are adjusted to minimize the difference between modeled and measured quantities (Michailovsky et al., 2012). Hydraulic model calibration has conventionally relied on surveyed bathymetric data (e.g., river bed elevation, channel geometry). However, river bathymetry data is not available in most parts of the world. Furthermore, ground surveys are very expensive and time consuming at catchment scale. Therefore, model parameters cannot be well constrained which generally leads to the problem of equifinality and induces large uncertainty in the calibration (Hostache et al., 2009). This impedes river modeling and operational flood forecasting for poorly monitored basins (e.g., the Mekong River, the Okavango River, the Brahmaputra River, etc.) (Birkinshaw et al., 2010; Milzow et al., 2011; Schneider et al., 2017; Siddique-E-Akbor et al., 2011).

In recent decades, advances in remote sensing observations have played an increasingly prominent role in hydrologic and hydraulic fields, and have promoted the estimates of key hydrologic and hydraulic variables (e.g., snow depth, soil moisture, water surface elevation (WSE), river width, discharge, and storage, etc. see a review by Lettenmaier et al. (2015)). Using satellite observations in model calibration can help better constrain model parameters and reduce calibration uncertainty because satellite observations (i.e. soil moisture, snow cover, etc.) have higher spatial coverage and contain information on land-surface processes that cannot be inferred from discharge (Hostache et al., 2009; Wanders et al., 2014). WSE derived from satellite altimetry is complementary to gauge data, especially in data-sparse and ungauged regions. Moreover, satellite altimetry provides spatially-distributed WSE data, which is valuable for calibration of distributed, 
non-uniform parameters. The number of studies using altimetry derived WSE in HD modeling is increasing with the richness of altimetry data sets. Liu et al. (2015) estimated discharge and water depth in ungauged rivers with coupled hydrologic-hydrodynamic models and inverse modeling methods using Envisat altimetry and Landsat imagery. They concluded that their modeling approach is able to estimate discharge and water depth for larger ungauged rivers, and the study implied the possibility of model calibration using remote-sensed data alone. Domeneghetti et al. $(2014,2015)$ demonstrated the suitability of WSE derived from altimetry for calibrating hydraulic models. Schneider et al. (2018a, 2018b) used CryoSat-2 for hydrodynamic model calibration and data assimilation and found a considerable improvement even for a well-gauged river. Several studies assess the value of wide swath altimetry data, as expected from the Surface Water and Oceanic Topography (SWOT) mission, to estimate HD model parameters and discharge using synthetic numerical experiments (Andreadis et al., 2007; Biancamaria et al., 2011; Durand et al., 2016, 2014; Frasson et al., 2017).

However, most of the studies focus on the identification of resistance, i.e. Manning's roughness coefficient, and most do not consider the spatial variability of resistance (Schumann et al., 2009). The channel bathymetry, defining the width and volume of water of the channel for a given water level, is either available from ground surveys or in most cases is approximated by uniform shapes (i.e. rectangle, triangle, or trapezoid) (Biancamaria et al., 2009; Domeneghetti, 2016). The challenge is to parameterize the channel bathymetry to improve HD simulations in data-sparse regions where only publicly available DEMs are used as input elevation data. To the best of our knowledge, a few studies calibrated the channel bathymetry (i.e. effective cross section in most cases) and resistance simultaneously. Yan et al. (2014) calibrated channel roughness and one uniform parameter (i.e. an uniform depth subtracted from river bed elevation which is retrieved from SRTM) to estimate channel bed elevation using Envisat altimetry data. The average mean absolute error (MAE) of water level at four gauging stations was $1.37 \mathrm{~m}$. Schneider et al. (2017) 
calibrated channel roughness, river bed elevation, and opening angle of a triangular cross section (XS) separately using CryoSat-2 and Envisat altimetry data. Their results show that the yearly amplitudes can be well simulated in terms of RMSE (0.83 m). Liu et al. (2015) took both uniform Manning's roughness and channel geometry (5 parameters) into account for HD model calibration using both altimetry and imagery, and showed promising results for ungauged river modeling. In addition, some studies estimated river bathymetry from synthetic SWOT data. For example, Yoon et al. (2012) estimated river bathymetry under an assumption of a rectangular channel geometry by assimilating synthetic SWOT observations of WSE. Durand et al. (2014) estimated reach-averaged roughness and bathymetry for discharge retrieval using synthetic SWOT. Oubanas et al. (2018a, 2018b) estimated discharge, river bathymetry, and bed roughness from synthetic SWOT measurements using data assimilation scheme. Moreover, a few studies attempted to calibrate channel geometry using SAR images with 2-D models. For example, Wood et al. (2016) calibrated the channel depth and roughness with SAR-derived flood extent from Envisat images. However, almost all these studies did not consider the variability of river morphology, and thus uniform parameters were assumed along the whole reach.

Clearly, as much data as possible should be used in the calibration, to describe the river morphologic characteristic along the studied reach and flow dynamics under different hydrologic conditions. However, calibration is routinely conducted using flow or stage at gauging stations, which likely leads to poor performance at other locations. This is a very important issue to be considered, especially for modeling of poorly gauged rivers. Getirana et al. (2013) explored how a spatially reduced amount of Envisat data influence discharge simulation. In their study, the use of a reduced number of virtual stations (VS) resulted in a slightly poorer performance. Similarly, Liu et al. (2015) investigated the sensitivity of model calibration to quantity and quality of Envisat derived water level observations and imagery. Their results showed that the calibration performance deteriorates as the number of Envisat altimetry observations decreases. However, 
short-repeat altimeters cannot capture the small-scale variability of river morphology due to the coarse resolution (80 km at Equator).

Many satellite altimetry missions have a spatial sampling interval of $80 \mathrm{~km}$ with 35 days repeat cycle or $315 \mathrm{~km}$ with 10 days cycle (see a review by Jiang et al. (2017b)). The coarse sampling is problematic for HD modeling in large, high-gradient, and data-sparse or ungauged rivers. Geodetic altimeters, e.g., CryoSat-2 mission, provide opportunities to test the effect of high spatial sampling data on river modeling. For example, Schneider et al. (2017, 2018b) used CryoSat-2 to calibrate a hydrodynamic model and a better result was achieved due to the unprecedentedly high spatial sampling. However, to the best of our knowledge, till now no research investigated the value of altimetry in calibrating spatially distributed roughness coefficient and bathymetry simultaneously.

Roughness coefficient and bathymetry are two unknown variables that challenge hydrodynamic modeling. However, these variables are not available from satellite observations, even the forthcoming SWOT satellite (Durand et al., 2014). We present an approach that calibrates bathymetry (i.e. effective cross section) and distributed roughness jointly using satellite altimetry derived observation of WSE in a regularized inversion framework. Consequently, this paper aims at investigating the effectiveness of altimetry in calibrating spatially distributed parameters. This work differs from previous studies in several ways. Firstly, we calibrate roughness and bathymetry simultaneously. We do not rely on any a-priori knowledge of these quantities. Secondly, we treat these quantities as distributed parameters instead of uniform value. Thirdly, we apply regularization methods to stabilize the inverse problems. Specifically, this study has three objectives:

1. Investigating how sampling patterns affect calibration of a one-dimensional (1D) HD river model. Different altimetry missions (i.e., geodetic and short-repeat altimeters) provide the opportunity to investigate how spatial and temporal resolutions affect calibration. 
2. Evaluating the influence of altimetry data accuracy on parameter calibration. The focus is to assess whether current accuracy of altimetry observations is sufficient in the context of hydrodynamic model calibration.

3. Exploring the capability of altimetry in calibrating two commonly used channel shapes, i.e. triangle and rectangle. These two geometries can be considered end members that encompass what we see in nature, and this simplification facilitates its application in data sparse regions.

In this paper, we design and conduct synthetic and real-world experiments to accomplish the three objectives. Synthetic numerical experiments, in which artificial altimetry observations are used, have been first conducted to understand the trade-off between spatial and temporal resolution and accuracy of satellite altimetry observation. Next, real-world data experiments have been carried out to evaluate the corresponding benefits on parameter calibration for an in-depth understanding of the value of satellite altimetry derived water surface elevation data.

\section{Materials}

\subsection{Study domain}

The study domain corresponds to the main stream of the Songhua River between Harbin and Jiamusi in China (Figure 1). This reach covers the midstream $433 \mathrm{~km}$ and corresponds to a drainage area of $138.5 \times 10^{3} \mathrm{~km}^{2}$. The Songhua River is the third largest river in terms of discharge in China. The entire drainage basin is $556.8 \times 10^{3} \mathrm{~km}^{2}$ and the corresponding average discharge is $2420 \mathrm{~m}^{3} / \mathrm{s}$. (Songliao River Conservancy Commission, 2015). Its headwaters rise in Greater Khingan Range and Paektu Mountain, where the Nenjiang River and the Second Songhua River form. The flow regime is driven by rainfall in the warm season (June to November) and by snow melt and rainfall during April to May. The river is icebound from mid-November to March and has a spring high flow when the snow melts during the spring thaw. During the summer season, the highest flows 
144 occur due to intensive rainfall (Songliao River Conservancy Commission, 2004). Mayi, Mudan, 145 and Woken are the main right tributaries while Hulan and Tangwang the main left tributaries

146 (Figure 1). The main channel is restricted by discontinuous dykes, and the flow field can thus be 147 well described by a 1D approximation for most parts of the Songhua River. We define three 148 subreaches divided by the four hydrometric stations (Figure 1). The first $222 \mathrm{~km}$ are very gentle $149(0.05 \mathrm{~m} / \mathrm{km})$ draining through hilly terrain. In the following $102 \mathrm{~km}$ of the reach, especially the 150 downstream $30 \mathrm{~km}$ close to Yilan, the channel is steeper, wider, and more shallow. The first half 151 of the last $109 \mathrm{~km}$ is narrower and deeper and the gradient of this sub-reach is steep at around 0.1 $152 \mathrm{~m} / \mathrm{km}$ (Jiang et al., 2017a). 


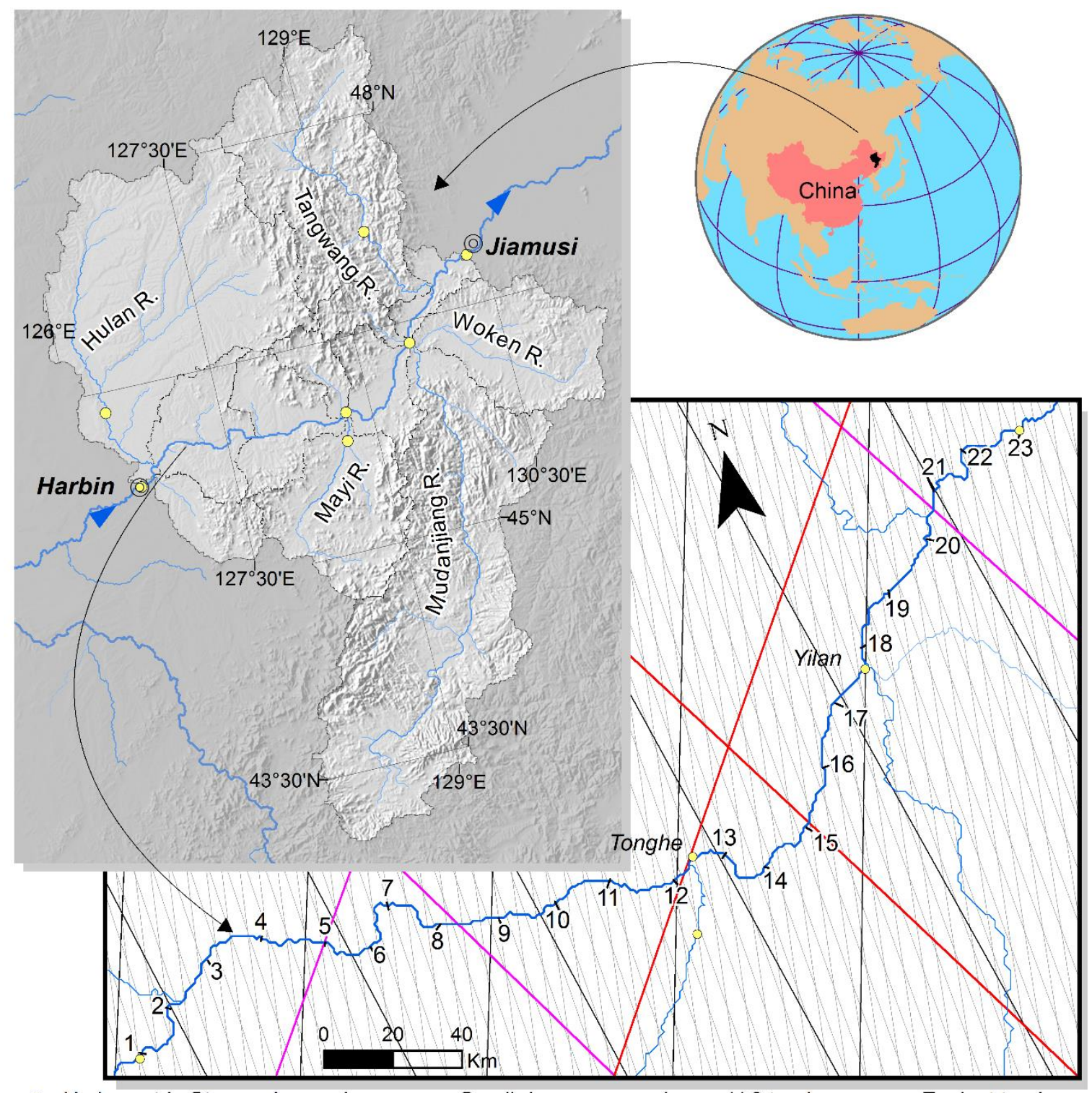

- Hydrometric St. $\sim \sim$ Large river $\sim$ Small river — Jason-1/-2 track Envisat track sub-catchment $\sim$ Medium river — Cross section — Jason-1 shifted track — CryoSat-2 track

Figure 1. Songhua River Basin. Songhua River system is composed of three parts, i.e. two headwaters Nenjiang River and Second Songhua River, and the main stream of Songhua river. In this study, a $433 \mathrm{~km}$ reach of the main stream is investigated, i.e. from Harbin to Jiamusi. Upper left: catchment delineation used for simulation of tributary flow. Bottom: ground tracks of multiple satellite altimetry missions, river channel, and cross sections (XS) used in HD model. Numbers indicate the XS setup in the HD model. 


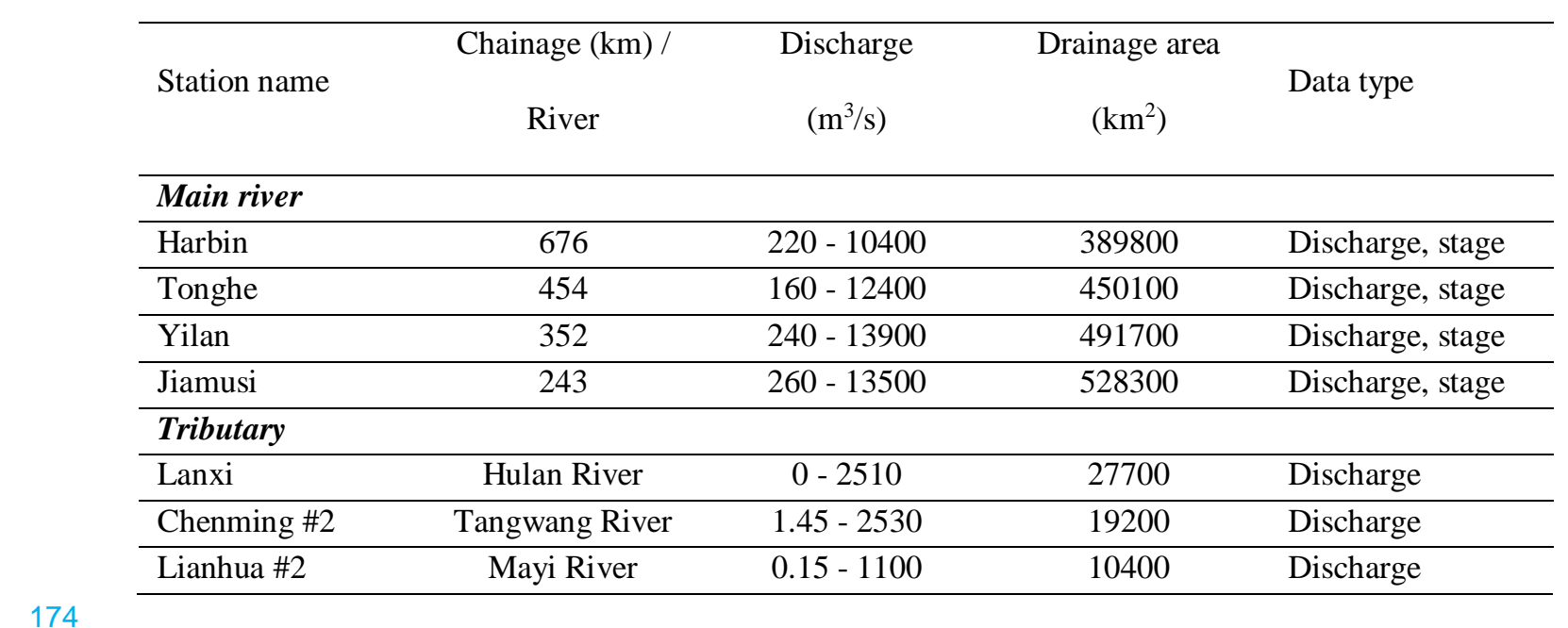

Daily meteorological data are obtained from the China Meteorological Data Service Center (http://data.cma.cn/en). The data sets include vapor pressure, relative humidity, air temperature, precipitation, wind speed, bright sunshine hours, and ground level temperature. The daily data is originally calculated from the accumulation or mean of four measurements at $6 \mathrm{~h}$ interval (i.e. 02:00, 08:00, 14:00, and 20:00 UTC+8). The data sets have been extensively used and data quality is assured by the China Meteorological Data Service Center.

\subsection{Hydrological data}

In this study, daily discharge and stage data of four gauge stations on the main river and discharge data of three stations distributed on three main tributaries for the 2007-2014 period are collected from the Hydrological yearbook issued by the Ministry of Water Resources of China (MWR, 2014), see Table 1. This national network is the only available source for daily gauged discharge and water level. The data set has been extensively used in the published literature.

Table 1 Main characteristics of gauge stations at the Songhua River and its tributaries

\subsection{Meteorological data}




\subsection{Altimetry data}

In this study, water level time series over river sections intersected by altimetry ground tracks are derived from Envisat, Jason-1, Jason-2, SARAL, and CryoSat-2 (Table 2). Geophysical Data Records (GDRs) of Jason-1/-2 and SARAL are downloaded from CNES AVISO+ program (Centre National D'Etudes Spatiales, Archiving, Validation and Interpretation of Satellite Oceanographic data, ftp://avisoftp.cnes.fr/AVISO/pub/). GDRs of Envisat are downloaded from CTOH data service (Center for Topographic studies of the Ocean and Hydrosphere, http://ctoh.legos.obs-

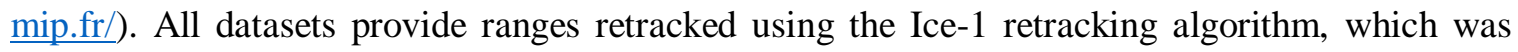
proven to be effective for continental water bodies (Frappart et al., 2006). Instrument corrections, atmospheric corrections (i.e. ionospheric refraction, dry tropospheric refraction, and wet tropospheric refraction), and geophysical corrections (i.e. solid Earth and pole tides) are also provided. The CryoSat-2 European Space Agency (ESA) L1b baseline C products are used to derive water level using the Narrow Primary Peak Threshold (NPPT) retracker (Jain et al., 2015). All altimetry data are then referenced to the EGM2008 (Pavlis et al., 2012) geoid model.

Note that SARAL left its repetitive orbit in July 2016 and switched to a geodetic orbit. SARAL satellite flies free of station keeping maneuvers and therefore there is a drift between successive ground tracks which are not repetitive any more. Although the cycle duration of 35 days is no longer kept, the new orbit has been chosen to preserve subcycles of 15 - 17 days with 1002 passes (Bonnefond et al., 2018). Given that SARAL has been in geodetic orbit since July 2016 only, we only use it for the synthetic numerical experiments but not for the real-world case study.

As systematic biases exist between altimetry missions, altimetry-derived WSE time series are compared with in-situ data. A detailed description of WSE time series construction and validation against in-situ data can be found in Jiang et al. (2017a). In addition, measurements observed during the cold season (Nov - Mar) are excluded because the river is frozen.

\section{Table 2 Summary of altimetry datasets used in this study}




\begin{tabular}{lllcc}
\hline Satellite & Data period & Altimeter & Frequency (day) & Inter-track \\
& & & & distance $(\mathrm{km})$ \\
\hline Envisat & $2007-2010$ & RA-2 & 35 & 80 \\
\hline Jason-1 & $2007-2013$ & Poseidon-2 & 10 & 315 \\
\hline Jason-2 & $2008-2014$ & Poseidon-3 & 10 & 315 \\
\hline CryoSat-2 & $2010-2014$ & SIRAL & 369 & 7.5 \\
\hline SARAL & $2016-2018$ & AltiKa & - & 2 \\
\hline
\end{tabular}

200

201

202

\# Jason-1 was moved to a new interleaved orbit with Jason-2 since Feb, 2009.

\section{Methodology}

\subsection{Setup of the hydrologic model}

One of the boundary conditions necessary for HD modeling is the runoff from the catchment. To calculate the input from the tributaries between Harbin and Jiamusi, the Xinanjiang (XAJ) hydrologic model is used. The XAJ is a conceptual watershed model which has been widely used for streamflow simulation and flood forecasting in China (Liu et al., 2009; Zhang et al., 2012; Zhao, 1992). It is developed based on the concept that runoff generation occurs on repletion of storage. That is to say, there is no runoff generated until the soil water deficit is replenished (Zhao, 1992). The structure of the XAJ model comprises four modules, i.e. evapotranspiration module, runoff production module, total runoff separation, and runoff concentration. Moreover, a snow module is coupled with XAJ, because snow melt in this region is one of the key hydrologic processes. In total, 19 parameters (see Table A1) are calibrated against observed streamflow.

The basic meteorological inputs of the XAJ model are precipitation, potential evapotranspiration (PET), and temperature (which controls snow accumulation and melt). Due to the uneven distribution of gauge stations, the common Thiessen method is used to calculate areaaveraged forcing data for each catchment. For the PET, the Penman-Monteith method (McMahon et al., 2013) is adopted. In the snowmelt component, the catchment is divided into a number of 
elevation zones and then adjusted precipitation, temperature, and PET are used to calculate melt water for each zone.

Model parameters for 3 catchments are calibrated against discharge using automatic calibration during 2007-2011 and validated during 2012-2014. The optimized parameters from the 3 gauged catchments are then transferred to neighboring ungauged catchments (see performance in Table A2).

\subsection{Setup of the hydrodynamic model}

MIKE HYDRO River is a new generation river modeling package - successor of the MIKE 11 river modeling system. It allows to model a variety of applications related to river hydraulics, flooding, forecasting as well as catchment dynamics and runoff. HD river simulations in MIKE HYDRO River use a one-dimensional (1D) simulation engine. The 1D engine solves the SaintVenant equations using an implicit 6-point finite-difference scheme (DHI, 2017). MIKE HYDRO River, as the previous versions, can solve the fully dynamic Saint-Venant equations as well as the kinematic and diffusive wave approximations.

This model is forced with observed daily discharge from the upstream end (Harbin) while normal depth is used as a downstream boundary condition. Normal depth is the depth at which uniform flow occurs in an open channel. In other words, the average slope of channel bed approximates energy slope. Therefore, normal depth can be calculated using Manning's equation. Furthermore, lateral inflows recorded or generated by the hydrologic model are also included in the model setup. The river network is downloaded from the HydroSHEDS dataset (Lehner and Grill, 2013). To explore the capability of altimetry data to infer river morphology, two commonly used channel shapes are investigated. The first one uses a triangular shape to conceptualize the channel with three parameters (Strickler coefficient $K_{s}, Z_{0}, \theta$ ) while the second one is a rectangle which also has three parameters, i.e. $K_{s}, Z_{0}$, and $b$ (Figure 2). Note that Strickler coefficient $K_{s}$ (also called Manning's $M$ in MIKE HYDRO River) is simply the reciprocal of Manning's n, which facilitates 
243 the calibration procedure. The reason to choose these two geometries is that the rectangle and 244 triangle can be considered end members that encompass what we see in nature, and this 245 simplification facilitates its application in data sparse regions (Chow, 1959; Neal et al., 2015). 246 Considering the computation cost, 23 XSs are equally spaced with a $\sim 20 \mathrm{~km}$ interval.

(a)

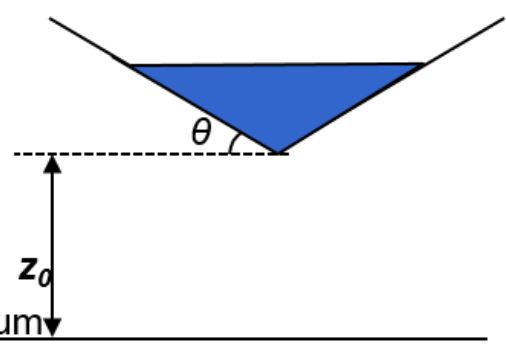

(b)

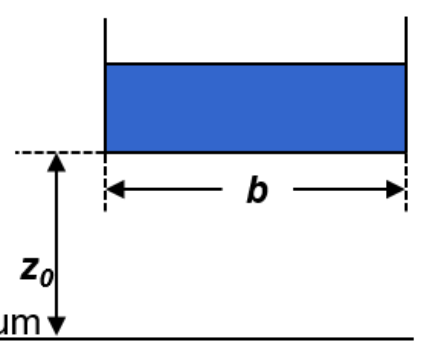

Figure 2. Schematizations of river cross sectional geometry. (a) Triangular geometry, including river bed elevation $Z_{0}$ and bank inclination angle $\theta$. (b) rectangular geometry, including $Z_{0}$ and river width $b$. Together with Strickler coefficient $K_{s}$, both shapes have 3 parameters for each cross section.

\subsection{Optimization methods}

Model calibration can be done manually or automatically by adjusting model parameters. Automated calibration is more efficient, objective, and reliable (Eckhardt et al., 2005). Automated model calibration can be achieved by different algorithms, such as gradient-based algorithms (e.g., Levenberg-Marquardt (Marquardt, 1963)), Monte Carlo approach (Beven and Binley, 1992), Shuffled Complex Evolution (Duan et al., 1992), Genetic Algorithm (Wang, 1991), etc. XAJ and MIKE HYDRO River are calibrated separately based on different approaches. XAJ is calibrated with Genetic Algorithm based on the objective of maximizing the Kling-Gupta efficiency (KGE) (Gupta et al., 2009).

Considering a large amount of parameters in the hydrodynamic model, a computationally efficient Levenberg-Marquardt (LM) algorithm (Marquardt, 1963) is used. However, a least-square inversion is unlikely to constrain this highly parameterized model. Therefore, in addition to observations, parameters can be constrained by regularization (e.g., smoothness, damping, or a 
priori information) to stabilize the ill-posed inverse problem (Pereverzyev et al., 2006). In our study, the objective function is composed of one data misfit term and three regularization terms that penalize abrupt changes of Strickler coefficient, datum, and width (or angle of triangle geometry) between neighboring XSs:

$\min o b j=\left\{\sum_{i=1}^{N d p}\left(H_{s, i}-H_{o, i}\right)^{2}+w_{1} \sum_{j=1}^{N X S}\left(Z_{0, j+1}-Z_{0, j}\right)^{2}+w_{2} \sum_{j=1}^{N X S}\left(K_{s, j+1}-K_{s, j}\right)^{2}+\right.$

$\left.w_{3} \sum_{j=1}^{N X S}\left(b_{j+1}-b_{j}\right)^{2}\right\}$

where: $Z_{o, j}, K_{s, j}$, and $b_{j}$ are parameters to be calibrated. $H_{s, i}$ and $H_{o, i}$ are simulated and observed WSE of $i^{\text {th }}$ point, respectively. $N d p$ and $N X S$ are the total number of altimetry observations and cross sections. $w_{i}$ are the regularization parameters (penalties) used to regularize the degree of smoothness. When triangle geometry is used, this equation is also applied but with parameter b replaced by $\theta$. A strong regularization (i.e. larger $w$ ) modifies the original problem, with the advantage of leading to a smooth solution; A weak regularization (i.e. smaller $w$ ) keeps the original problem almost unchanged, but can produce wildly oscillating solutions. By adjusting the weight parameter $w$, any inverse problem can be stabilized and a unique solution can be found (Finsterle and Kowalsky, 2011).

\subsection{Synthetic calibration experiments: setup and assumptions}

In order to explore the value of WSE data from different satellite missions, synthetic calibration experiments are first conducted. If the synthetic data applied to the model calibration fails to replicate the synthetic 'truth', it is unlikely to work in real world (Su et al., 2016). Here we conduct synthetic experiments in the following steps (Figure 3): (a) synthetic observations are created through one model realization to serve as 'truth'; (b) the synthetic 'truth' is then perturbed with different magnitudes of observation errors; (c) these perturbed observations are sampled consistent with altimetry data, i.e. at the exact same locations and times to represent altimetry-like observations; (d) these synthetic altimetry observations are used to calibrate the model. It is tested 

process is conducted using MATLAB combined with .NET (C\#) and MIKE HYDRO River.

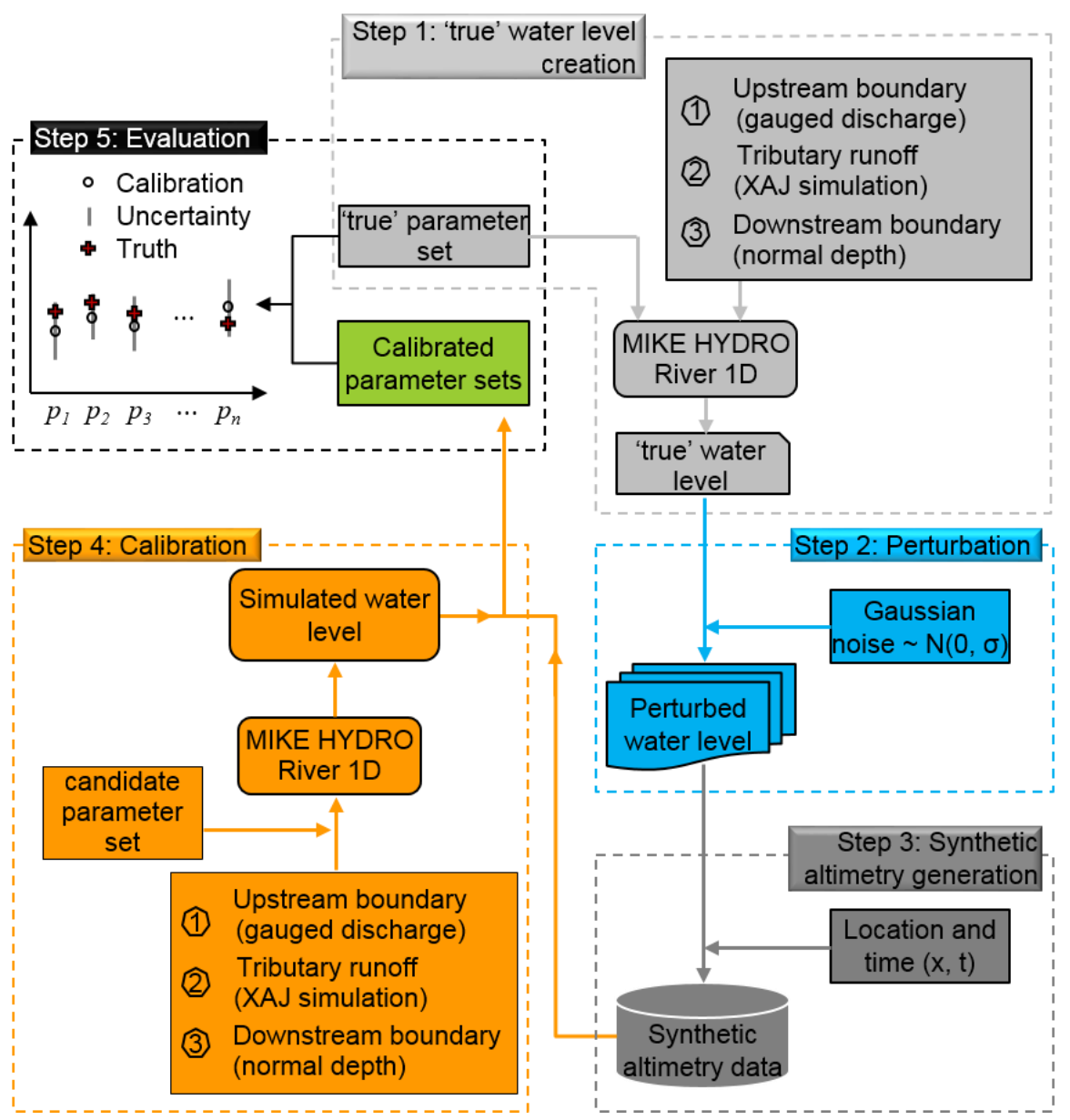

Figure 3. Flowchart of synthetic modeling experiment. The framework has five steps as illustrated in different colors, consisting of creation of the truth, perturbation, generation of synthetic altimetry data, calibration, and evaluation. In the upper left corner, $p_{i}$ indicate parameters of each cross section.

The synthetic experiments assume that the perturbed water level fully represents all the uncertainties in the modeling system, which allows us to focus only on the calibration. With this assumption, Gaussian white noise is added to the 'truth' to create synthetic observations:

$$
h^{s}(x, t)=h^{t}(x, t)+\varepsilon
$$


where $h^{t}$ is the 'truth' observation, and $\varepsilon$ is the noise term, which follows a Gaussian

distribution with zero mean and specified standard deviation $\sigma$, i.e. $\varepsilon \sim N\left(0, \sigma^{2}\right)$. Gaussian distribution is checked by performing a normality test based on in-situ measurements from three gauge stations. The synthetic altimetry data $\left(h^{s}\right)$ are sampled according to the location $(x)$ and time $(t)$ of real altimetry observations. Different values of $\sigma$ are used to evaluate the effects of altimetry observation accuracy on parameter estimates. Specifically, $0.4 \mathrm{~m}$ is set as normal standard based on current altimetry observation accuracy; while, $0.2 \mathrm{~m}$ is used for higher accuracy scenario, which is seldom reported for current altimetry datasets. The experiments conducted are listed in Table 3 . As mentioned before, two cross-section geometries are used for different scenarios. The scenarios are conducted using each of the five altimetry data sets and the integration of all data sets. In order to make a fair comparison, we use very similar number of altimetry observations.

Under the assumption that parameters of adjacent XSs are similar, we generated the 'true' values of parameters $K_{s}, b$, and $\theta$ for each XS using a sinusoidal model, the amplitude of which covers a reasonable range of corresponding parameter values. For example, $K_{s}$ is assumed to be between 20 and $60 \mathrm{~m}^{1 / 3} \mathrm{~s}^{-1}$ and $b$ ranges from 200 to $1000 \mathrm{~m}$. While for the river bed datum $Z_{0}$, we used piecewise linear function within the range of $[70,110] \mathrm{m}$.

Table 3 Summary of HD model synthetic calibration experiments

\begin{tabular}{|c|c|c|c|c|c|c|}
\hline Triangular & & & Bank & Rectangular & & Channel \\
\hline $\begin{array}{l}\text { geometry } \\
\text { (T) }\end{array}$ & $\begin{array}{l}\text { Strickler's, } K_{s} \\
{\left[\mathrm{~m}^{1 / 3} \mathrm{~s}^{-1}\right]}\end{array}$ & $\begin{array}{l}\text { Datum, } Z_{0} \\
{[\mathrm{~m}]}\end{array}$ & $\begin{array}{l}\text { inclination } \\
\text { angle } \theta[\mathrm{deg}]\end{array}$ & $\begin{array}{l}\text { geometry } \\
\text { (R) }\end{array}$ & $\begin{array}{l}\text { Strickler's, Datum, } \\
K_{s}\left[\mathrm{~m}^{1 / 3} \mathrm{~s}^{-1}\right] Z_{0}[\mathrm{~m}]\end{array}$ & $\begin{array}{l}\text { width } b \\
{[\mathrm{~m}]}\end{array}$ \\
\hline
\end{tabular}

Scenario A: altimetry measurement error $\sigma=0.2 \mathrm{~m}$

\begin{tabular}{llllllll}
\hline TA1 & $\checkmark$ & $\boldsymbol{x}$ & $\boldsymbol{x}$ & RA1 & $\checkmark$ & $\mathbf{x}$ & $\mathbf{x}$ \\
\hline TA2 & $\boldsymbol{x}$ & $\checkmark$ & $\mathbf{x}$ & RA2 & $\mathbf{x}$ & $\checkmark$ & $\mathbf{x}$ \\
\hline TA3 & $\boldsymbol{x}$ & $\boldsymbol{x}$ & $\checkmark$ & RA3 & $\mathbf{x}$ & $\mathbf{x}$ & $\checkmark$ \\
\hline TA4 & $\checkmark$ & $\checkmark$ & $\mathbf{x}$ & RA4 & $\checkmark$ & $\checkmark$ & $\mathbf{x}$ \\
\hline
\end{tabular}




\begin{tabular}{llllllll}
\hline TA5 & $\checkmark$ & $\boldsymbol{x}$ & $\checkmark$ & RA5 & $\checkmark$ & $\mathbf{x}$ & $\checkmark$ \\
\hline TA6 & $\boldsymbol{x}$ & $\checkmark$ & $\checkmark$ & RA6 & $\boldsymbol{x}$ & $\checkmark$ & $\checkmark$ \\
\hline TA7 & $\checkmark$ & $\checkmark$ & $\checkmark$ & RA7 & $\checkmark$ & $\checkmark$ & $\checkmark$ \\
\hline
\end{tabular}

Scenario B: altimetry measurement error $\sigma=0.4 \mathrm{~m}$

\begin{tabular}{clllllll}
\hline TB1 & $\checkmark$ & $\mathbf{x}$ & $\mathbf{x}$ & RB1 & $\checkmark$ & $\mathbf{x}$ & $\mathbf{x}$ \\
\hline TB2 & $\mathbf{x}$ & $\checkmark$ & $\mathbf{x}$ & RB2 & $\mathbf{x}$ & $\checkmark$ & $\mathbf{x}$ \\
\hline TB3 & $\boldsymbol{x}$ & $\boldsymbol{x}$ & $\checkmark$ & RB3 & $\mathbf{x}$ & $\mathbf{x}$ & $\checkmark$ \\
\hline TB4 & $\checkmark$ & $\checkmark$ & $\mathbf{x}$ & RB4 & $\checkmark$ & $\checkmark$ & $\mathbf{x}$ \\
\hline TB5 & $\checkmark$ & $\mathbf{x}$ & $\checkmark$ & RB5 & $\checkmark$ & $\mathbf{x}$ & $\checkmark$ \\
\hline TB6 & $\mathbf{x}$ & $\checkmark$ & $\checkmark$ & RB6 & $\mathbf{x}$ & $\checkmark$ & $\checkmark$ \\
\hline TB7 & $\checkmark$ & $\checkmark$ & $\checkmark$ & RB7 & $\checkmark$ & $\checkmark$ & $\checkmark$
\end{tabular}

NB: $\checkmark$ indicating calibrated variable; $x$ indicating known variable, i.e. the same as the synthetic 'truth'.

\subsection{Model calibration with real-world data}

After the synthetic experiments, real-world data from different altimetry missions are used to estimate Strickler coefficient and datum. Given that river width does not change dramatically in normal-flow year, we choose rectangular shape to approximate channel geometry. Because three parameters cannot be jointly calibrated (presented in results section), we measured channel width from Landsat images sensed during August. regardless of quality of observations) used in the synthetic experiments, only valid observations during the period between 2007 and 2014 are used. Specifically, outliers and all observations during Nov and Mar are discarded. Considering that only 49 observations from Jason-1 are available, Jason-1 is not used for separate calibration. Therefore, for the real-world case, we have 5 calibration experiments, which are conducted using CryoSat-2, Envisat, Jason1 \& Jason 2, Jason 2, and all data sources combined, respectively. 


\subsection{Evaluation criteria}

The performance of synthetic experiments is assessed at 95\% confidence interval (CI) in terms of coverage, sharpness, and also assessed by the continuous ranked probability score (CRPS) (Gneiting et al., 2005). Coverage is defined by the percentage of synthetic truth parameters that fall within the calibrated parameter interval. At $95 \%$ CI, which is expected to include $95 \%$ of the synthetic truth parameters, the closer to $95 \%$ coverage is, the better calibration performs. Therefore, the perfect value is $95 \%$. Sharpness is the average width of the calibrated parameter interval. A smaller width is preferred. CPRS does not focus on any specific point of the probability distribution, but considers the distribution of the calibrated parameter as a whole. It is generally used to assess probabilistic predictions. Here we use it to compare the calibrated parameters with synthetic truth. Assuming normally distributed parameter estimates, CRPS can be calculated with the following formula:

$$
C R P S=\frac{1}{N X S} \sum_{n=1}^{N X S} \sigma\left[\frac{x_{n}^{o}-x_{n}^{f}}{\sigma}\left(2 \Phi\left(\frac{x_{n}^{o}-x_{n}^{f}}{\sigma}\right)-1\right)+2 \phi\left(\frac{x_{n}^{o}-x_{n}^{f}}{\sigma}\right)-\frac{1}{\sqrt{\pi}}\right]
$$

In which, $\mathrm{n}$ is the number of XS (NXS =23); $\sigma$ is the standard deviation of the calibrated parameter;

$x_{n}^{f}$ and $x_{n}^{o}$ are the calibrated and truth parameters, i.e. $K_{s}, Z_{0}, \theta$ and $b$; $\Phi$ and $\phi$ are the cumulative distribution function and probability density function of the standard normal distribution, respectively. CRPS takes both coverage and sharpness into consideration. The smaller CRPS, the better performance of the calibration.

Streamflow predictability of the hydrologic-hydrodynamic model can be graphically and statistically evaluated against in-situ data. Four statistical metrics are used as evaluation criteria, i.e. the Nash-Sutcliffe efficiency (NSE) the percentage of bias (PBIAS), the determination coefficient $\left(R^{2}\right)$, and the root-mean-square error $(R M S E)$. 


\section{Results}

\subsection{Synthetic experiments}

\subsubsection{Calibration experiments with different parameter combinations}

For both schematizations of channel geometry, altimetry can constrain some combinations of parameters (Table 4). However, when $\theta$ (or $b$ ) and $K_{s}$ are jointly calibrated, the 'truth' cannot be recovered. Therefore, the complete parameter triplet cannot be constrained without further information. The reason is that $\theta$ (or $b$ ) and $K_{s}$ are strongly correlated (see Figure B1 and B2). On the other hand, we can see once $\theta$ (or $b$ ) is known, $K_{s}$ and $Z_{0}$ can be calibrated jointly by altimetry data. Nevertheless, it should be acknowledged that all missions can constrain one single calibration parameter, and constrain two calibration parameters to different degree.

Table 4 General summary of calibration of different parameter sets

\begin{tabular}{llll}
\hline \multicolumn{2}{c}{ Triangular channel } & \multicolumn{2}{c}{ Rectangular channel } \\
\hline Combination & Successfully & Combination & Successfully \\
& & & \\
\hline$\left[K_{s}\right]$ & Yes & {$\left[K_{s}\right]$} & Yes \\
\hline$\left[Z_{0}\right]$ & Yes & {$\left[Z_{0}\right]$} & Yes \\
\hline$[\theta]$ & Yes & {$[b]$} & Yes \\
\hline$\left[K_{s}, Z_{0}\right]$ & Yes & {$\left[K_{s}, Z_{0}\right]$} & Yes \\
\hline$\left[K_{s}, \theta\right]$ & No & {$\left[K_{s}, b\right]$} & No \\
\hline$\left[Z_{0}, \theta\right]$ & Yes & {$\left[Z_{0}, b\right]$} & Yes \\
\hline$\left[K_{s}, Z_{0}, \theta\right]$ & No & {$\left[K_{s}, Z_{0}, b\right]$} & No \\
\hline
\end{tabular}

Generally, coverage is above $80 \%$ except that of parameter $b$, which underestimated uncertainty. Overall, experiments using different altimetry data sets have different performance although the number of observations is similar for different experiments. Table $\mathrm{C} 1$ summarizes the performance of all successful calibrations in terms of coverage, sharpness, and CRPS for the rectangular XS geometry (similar results were found for the triangular geometry). In the following sections, we present the effect of sampling density and observation accuracy on model calibration. 


\subsubsection{Impact of sampling pattern}

Figure 4 shows the calibration of experiment RA1, i.e. calibration of Strickler coefficient $K_{s}$. All five missions can recover the synthetic truth to some degree. However, it is noticeable that CryoSat-2 and SARAL significantly outperform the rest regarding sharpness and CRPS values (Table $\mathrm{C} 1$ and Figure 4). The variability of $K_{s}$ is excellently recovered (Figures 4a and 4e). As the spatial sampling resolution degrades (i.e. 10 VSs for Envisat, 5 VSs for Jason-1, and 2 VSs for Jason-2, refer to the black cross in Figure 4), the parameters are getting less constrained. For example, Jason-1 with $5 \mathrm{VSs}$, can recover the truth somewhat although the uncertainty is quite large. It should be noted that there are less observations for each VS of Jason-1 than Jason-2. However, it is clearly shown in Figure 4d that two VSs are not sufficient to constrain the variability over a long distance, and only those XSs close to VSs are well calibrated (see black crosses). As expected, pooling data from all missions, clearly performs the best with a very small sharpness (4.5 $\mathrm{m}^{1 / 3} / \mathrm{s}$ ). Even assuming less accurate data (i.e. $40 \mathrm{~cm}$ standard error), sharpness and CRPS are still much better than those of any single mission with high data accuracy (see Table C1). Meanwhile, Strickler coefficient $K_{s}$ is very sensitive to WSE. Or to put it in another way, as the separation between XS and VS increases, the uncertainty of $K_{s}$ increases, for example around XS 15 in Figure $4 b$ (see also Figure $4 c$ and Figure $4 d)$. 

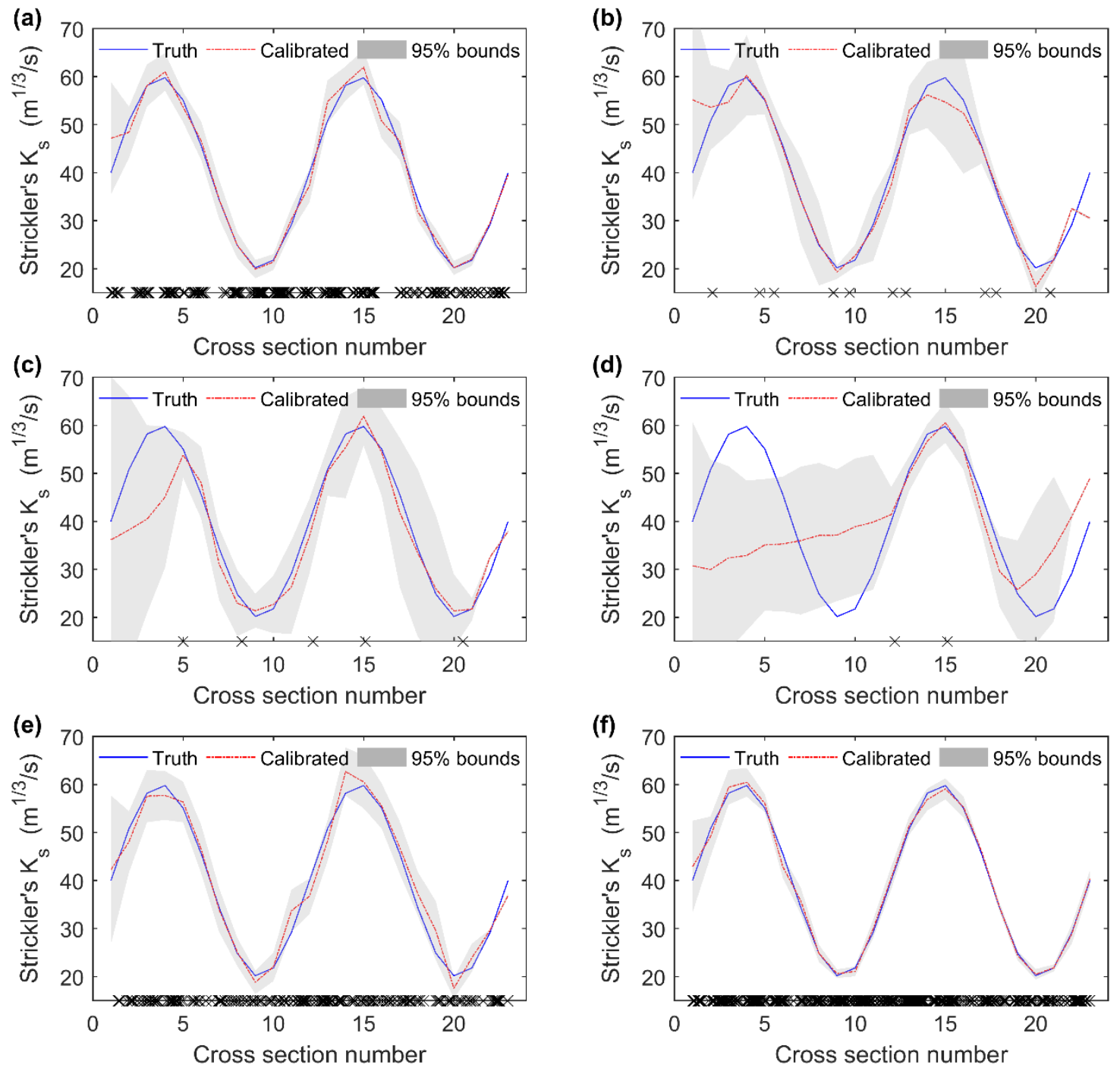

389 Figure 4. Comparison of calibrations of Strickler coefficient $K_{s}$ using synthetic data from different altimetry missions, corresponding to experiment RA1. (a) calibration using CryoSat-2 with very dense samples along the river; (b) calibration using Envisat with $10 \mathrm{VSs}$; (c) calibration using Jason-1 with 5 (2 before Feb 2009 and 3 after Feb 2009) VSs; (d) calibration using Jason-2 with 2 VSs; (e) calibration using SARAL with geodetic orbit, and (f) calibration using all altimetry missions. Crosses along the $\mathrm{x}$-axis indicate the nominal VS stations. is apparent that CryoSat-2 and SARAL by far outperform the other three missions and are practically as good as the integration of all missions. In terms of CRPS, CryoSat-2, SARAL and 
398 Envisat are within $0.15 \mathrm{~m}$ while Jason-2 is over $0.3 \mathrm{~m}$. As the two VSs of Jason-2 are located close

399 to XS 12 and 15, parameters located in-between and downstream are well calibrated while those

400 upstream have wide uncertainty intervals (Figure 5d). Meanwhile, the uncertainty is larger between

401 VSs as illustrated in inset plots (see grey bumps in Figure 5). These results indicate that dense

402 sampling pattern increases parameter sharpness though all missions can recover datum to some

403 extent. By comparing Figures 5b and 5c, Jason-1, despite its higher temporal sampling, is not

404 superior to Envisat in this calibration, mainly because Jason-1 has sparser inter-track distance, i.e.,

405 lower spatial sampling resolution. The purpose of comparing these five missions is to analyze the

406 trade-off between spatial and temporal resolution and not the value of high temporal resolution per 407 se. 
(a)

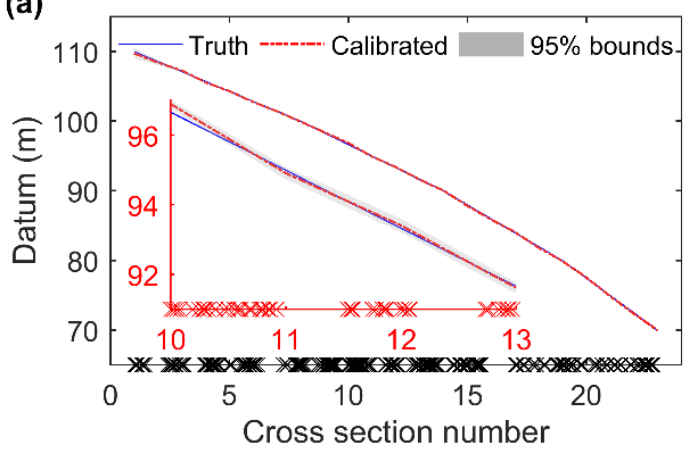

(c)

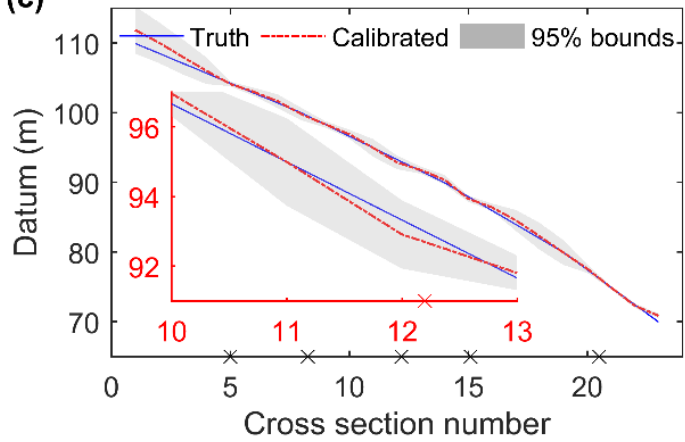

(e)

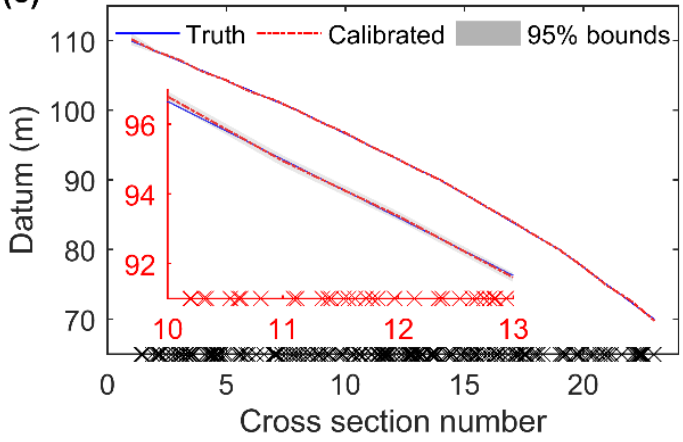

(b)

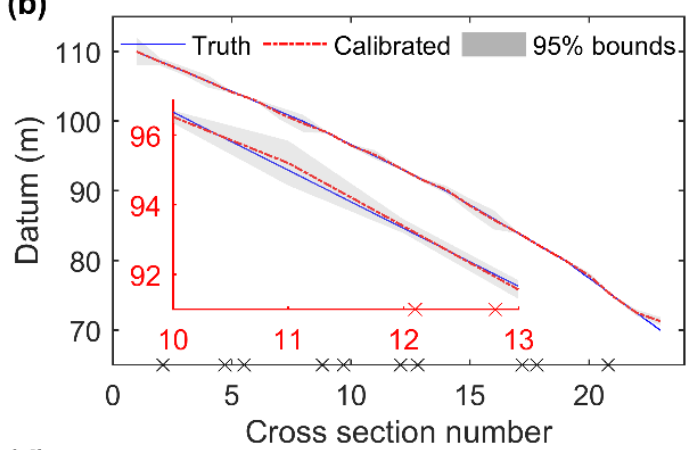

(d)

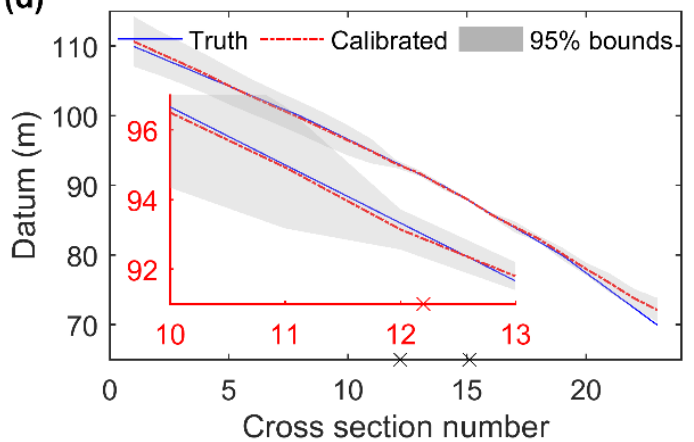

(f)

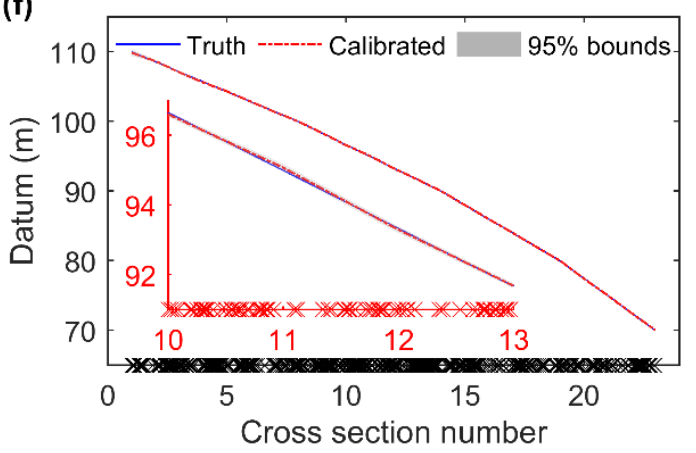

Figure 5. Similar to Figure 4, but for river bed elevation, corresponding to experiment RA2. Inset shows a zoomed-up plot.

Experiment RA4 calibrates Strickler coefficient $K_{s}$ and datum $Z_{0}$ simultaneously, i.e. totally 46 parameters are calibrated. These parameters can be well recovered by CryoSat- 2 and SARAL, but to a lesser extent by Envisat, Jason-1, and Jason-2 (Figure 6). As shown in Figure 6, the variability of $K_{s}$ is much better recovered by CryoSat- 2 than the others. For the latter, only some of the Strickler coefficients are approaching the truth (Figure $6 \mathrm{~g}$ ). Nevertheless, $Z_{0}$ is constrained by all missions in a similar manner although Jason-1/-2 can hardly constrain $Z_{0}$ of the upstream and downstream portions. One interesting fact is that compared to Jason-2, Jason-1 has much better performance, 
419 which suggests three more VSs play a very important role although each of them has less 420 observations than Jason-2. In addition, integration of all missions does not improve calibration 421 significantly compared with CryoSat-2 and SARAL although a much higher number of 422 observations are used (see performance measures in Table C1).

423 Surprisingly, high temporal sampling does not constrain parameters with sharper confidence 424 interval at exact VS locations. As depicted in Figure 6e, Jason-1 with 10-day repeat period does 425 recover $K_{s}$ at most VSs but the uncertainty is even larger than that of CryoSat-2 which has a 369-

426 day repeat period. When all data are used, the sampling is very dense and a much better result is 427 achieved (Figures 6k and 61). 

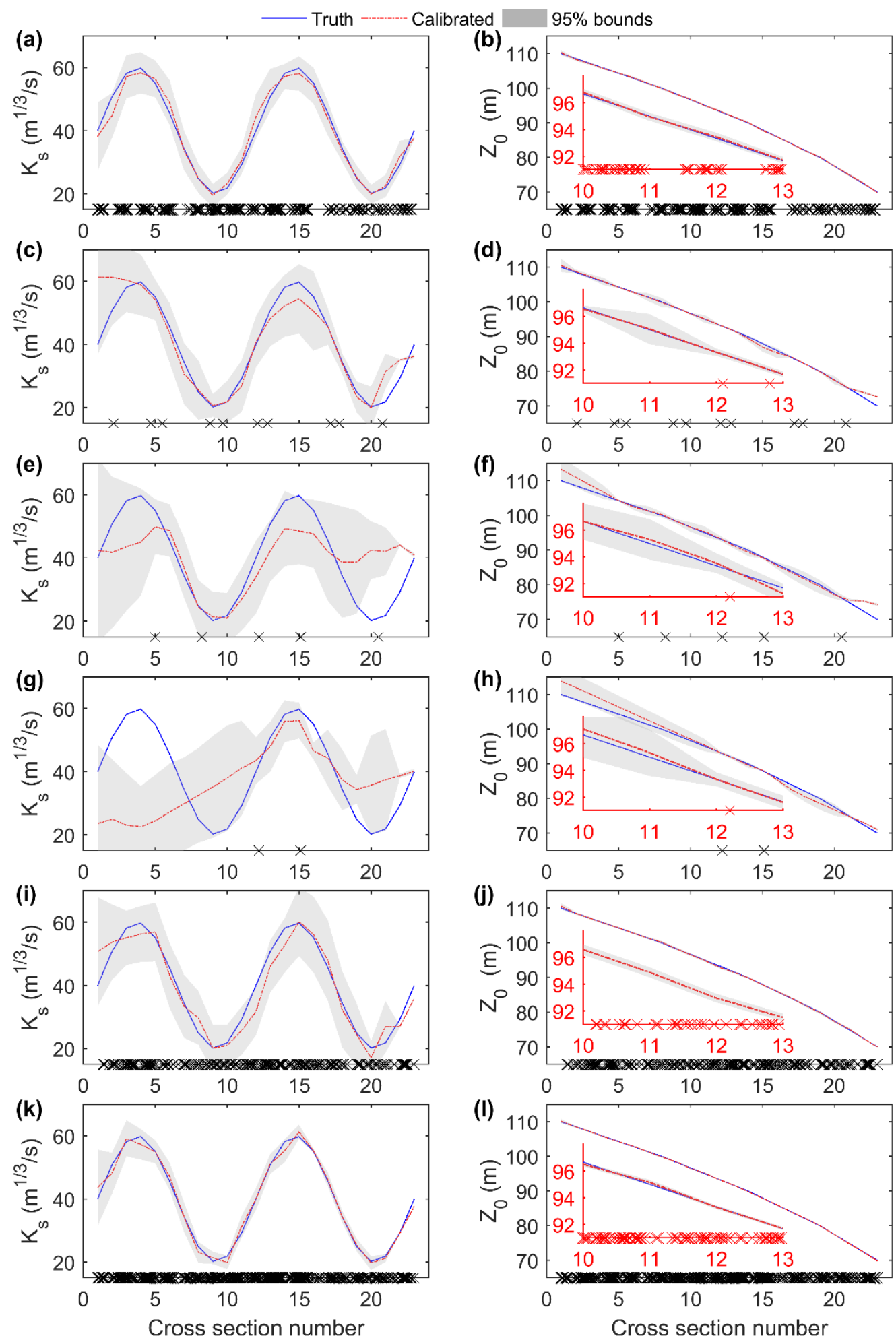

Figure 6. Comparison of calibrations of both Strickler coefficient and river bed elevation using

430 synthetic data, corresponding to scenario RA4. Inset shows a zoomed-up plot. (a) and (b) are 431 calibrated using CryoSat-2 data; (c) and (d) are calibrated using Envisat data; (e) and (f) are 
calibrated using Jason-1 data, (g) and (h) are calibrated using Jason-2 data, (i) and (j) are calibrated using SARAL data, and (k) and (l) are calibrated using data from all missions. Crosses along the $\mathrm{x}$-axis indicate the nominal VS stations.

\subsubsection{Impact of accuracy of satellite observation}

In order to explore the impact of data accuracy on model calibration, scenario B is conducted and compared to scenario A. The performance measures are also summarized in Table C1. Overall, higher data accuracy does decrease parameter uncertainty of most experiments but not proportionally, especially for river bed datum. In general, reliability increases but sharpness decreases, and sometimes increased reliability is over-compensated by the loss of sharpness, i.e. coverage is over $95 \%$. In some cases, the CRPS does not really improve significantly, which implies that higher observation accuracy does not increase the value of the observation in the context of hydraulic parameter inversion. Nevertheless, for single parameter calibration (i.e. $K_{s}$ or $Z_{0}$ instead of $K_{s}$ and $Z_{0}$ jointly), parameter identifiability increases with increasing observation accuracy (see sharpness and CRPS in Table C1).

\subsection{Calibration with real-world altimetry observations}

The results of model calibration are reported below distinguishing different real-world data. Model performance is first evaluated by the sharpness of parameters, and then by comparing simulated water level against altimetry observations and in-situ observations. Model performance is summarized in Table 5. In general, all experiments are performing fairly well in terms of RMSE. While considering model parameters, CryoSat-2 and Envisat are much better in constraining river datum, which is consistent with the synthetic experiments. More detailed channel morphological characterization is presented followed by model evaluation. 
Table 5 Measures of calibrated parameters using real-world observations and evaluation of simulated water level against altimetry-derive water level and in-situ observations at two internal gauge stations

\begin{tabular}{|c|c|c|c|c|c|c|c|c|}
\hline \multirow{2}{*}{$\begin{array}{l}\text { Experi } \\
\text { ment }\end{array}$} & \multirow{2}{*}{$\begin{array}{l}\text { Data } \\
\text { source }\end{array}$} & \multirow{2}{*}{$\begin{array}{c}\text { Period of } \\
\text { data }\end{array}$} & \multirow{2}{*}{$\begin{array}{l}\text { No. of } \\
\text { obs. }\end{array}$} & \multirow{2}{*}{$\begin{array}{c}\text { Sharpness of } \\
K_{s}\left(\mathrm{~m}^{1 / 3} / \mathrm{s}\right)\end{array}$} & \multirow{2}{*}{$\begin{array}{c}\text { Sharpness } \\
\text { of } Z_{0}(\mathrm{~m})\end{array}$} & \multicolumn{3}{|c|}{$R M S E(\mathrm{~m})$} \\
\hline & & & & & & Alt & $\mathrm{T}$ & $\mathrm{Y}$ \\
\hline S1 & CryoSat-2 & 2010-2014 & 261 & 45.8 & 2.87 & 1.23 & 0.33 & 0.48 \\
\hline S2 & Envisat & $2007-2010$ & 244 & 49.0 & 3.86 & 1.59 & 0.36 & 0.45 \\
\hline S3 & JA1 \& JA2 & 2007-2014 & 319 & 52.6 & 4.37 & 0.89 & 0.35 & 0.40 \\
\hline S4 & JA2 & 2008-2014 & . 270 & 53.3 & 6.72 & 0.71 & 0.37 & 0.42 \\
\hline S5 & all & 2007-2014 & 824 & 29.1 & 1.50 & 1.07 & 0.33 & 0.51 \\
\hline
\end{tabular}

NB: Alt: evaluation of simulated water level against altimetry observation; T: evaluation at Tonghe station, evaluation time period: 2010 - 2014; Y: evaluation at Yilan station, evaluation time period: 2007 - 2014.

\subsubsection{Channel roughness calibration}

Figure 7 displays the calibrated channel roughness in terms of Strickler coefficient $K_{s}$. The five experiments somewhat agree with each other. The roughness generally increases from upstream to downstream. The $K_{s}$ value is in the range of 30 to $85 \mathrm{~m}^{1 / 3} / \mathrm{s}$. The upstream roughness is smaller compared to natural rivers (Chow, 1959). This small roughness can be explained by the wellconfined and stable dykes and groynes in this part of the river system. The smallest $K_{s}$ occurs in the most upstream portion, where a very wide reservoir has been recently constructed. As the river flows through a floodplain area and the confluence of lateral rivers, the roughness increases to a maximum corresponding to $K_{s} \sim 35 \mathrm{~m}^{1 / 3} / \mathrm{s}$ at the Sanxing Shoal, where the channel is very shallow and wide.

However, the calibrated roughness of the five experiments has some discrepancies. For the upstream XSs, $K_{s}$ is not consistent among experiments. This can be explained by the extremely wide channel (> $3 \mathrm{~km})$ where flow velocities are very low and therefore there is no sensitivity to $K_{s}$. The variability of $K_{s}$ between XS 15 and 20 is not identified by Jason-1 and Jason-2 due to the lack of observations (Figure 7c). As revealed by synthetic experiments, Jason-2 with two VSs, 
474 cannot constrain the variability of $K_{s}$ along the entire reach although it achieved similar RMSE 475 value (Figure $7 \mathrm{~d}$ and Table 5).
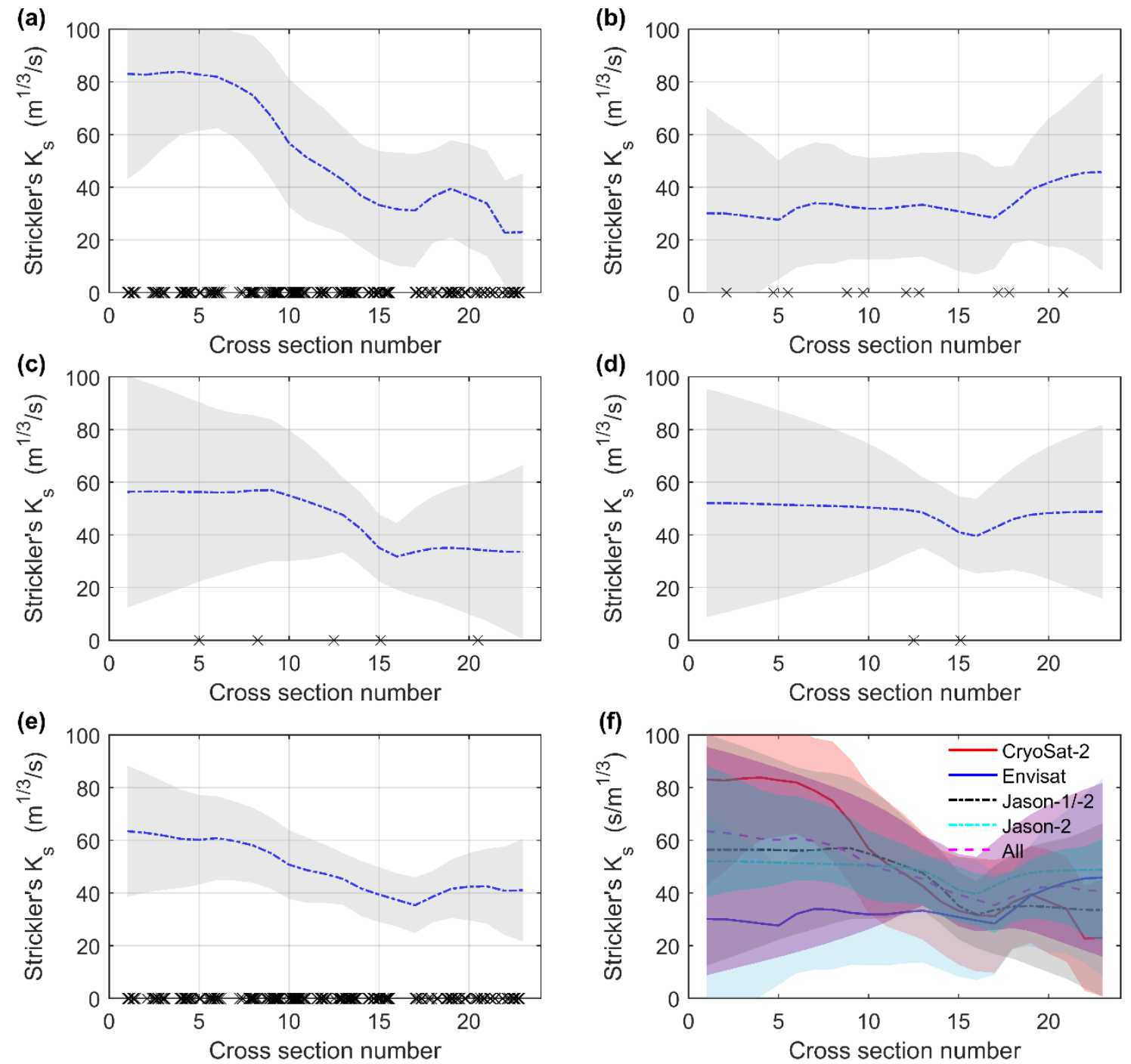

477 Figure 7. Comparison of calibrations of Strickler coefficient $K_{s}$ using real-world observations from

478 different altimetry missions. (a) CryoSat-2, (b) Envisat, (c) Jason-1 and Jason-2, (d) Jason-2, (e) all 479 missions, and (f) a comparison of five calibrated results. VS locations are indicated by crosses along 480 the $\mathrm{x}$-axis.

\subsubsection{Channel shape calibration}


The datum (river bed elevation) generally agrees well with each other (Figure 8). Near XS 5, there is a drop due to the reservoir. Then the channel datum is fairly gentle at $0.066 \mathrm{~m} / \mathrm{km}$. Close to Yilan station, the channel slope gets steeper as the channel shrinks. CryoSat-2 confined the datum within a $2.9 \mathrm{~m}$ interval. By and large, Envisat captured the spatial variability of datum although it missed the artificial drop upstream. Similarly, combined JA-1 and JA-2 (Figure 8c) also identified the variability. Clearly, Jason-2 cannot constrain the variability except at the two VSs (Figure 8d). Similar to the synthetic experiments, pooling of all missions achieves the same characteristics but smaller uncertainty $(1.5 \mathrm{~m})$.
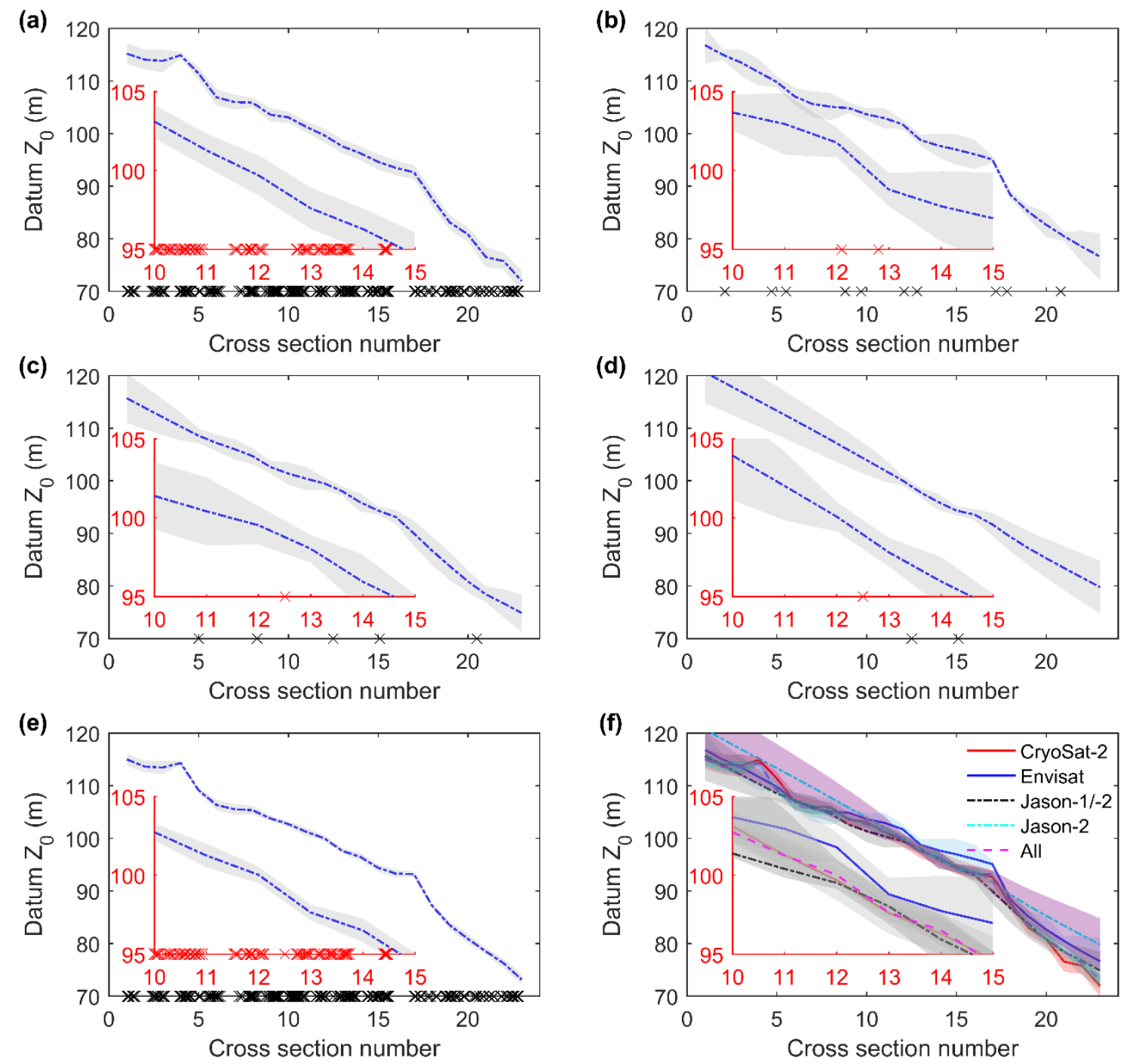

491 Figure 8. Similar to Figure 7, but for datum, i.e. river bed elevation. 


\subsubsection{Simulated hydraulic properties}

Simulated hydraulic characteristics are plotted in Figure 9. All flow in the channel is subcritical, with Froude numbers ranging from 0.02 to 0.30 . Froude number and water slope are in good agreement (Figures 9a and 9d). The Froude number is relatively stable for most of the channel while high Froude numbers appear at chainage of around $70 \mathrm{~km}$ and $345 \mathrm{~km}$, where high-gradient drops are present (Figure 9e). Viewed in longitudinal profile, these hydraulic factors are plausible. Close to the two drops, mean velocities of flow are larger, and higher Froude numbers occur (Figure 9). For the second drop, the velocity did not occur at the location of the steepest slope. Instead, it was located slightly downstream from the area of the steepest slope. The average simulated water depth varies from 0.8 to $2.0 \mathrm{~m}$ during low flow season, and from 1.6 to $3.5 \mathrm{~m}$ during high flow season. 


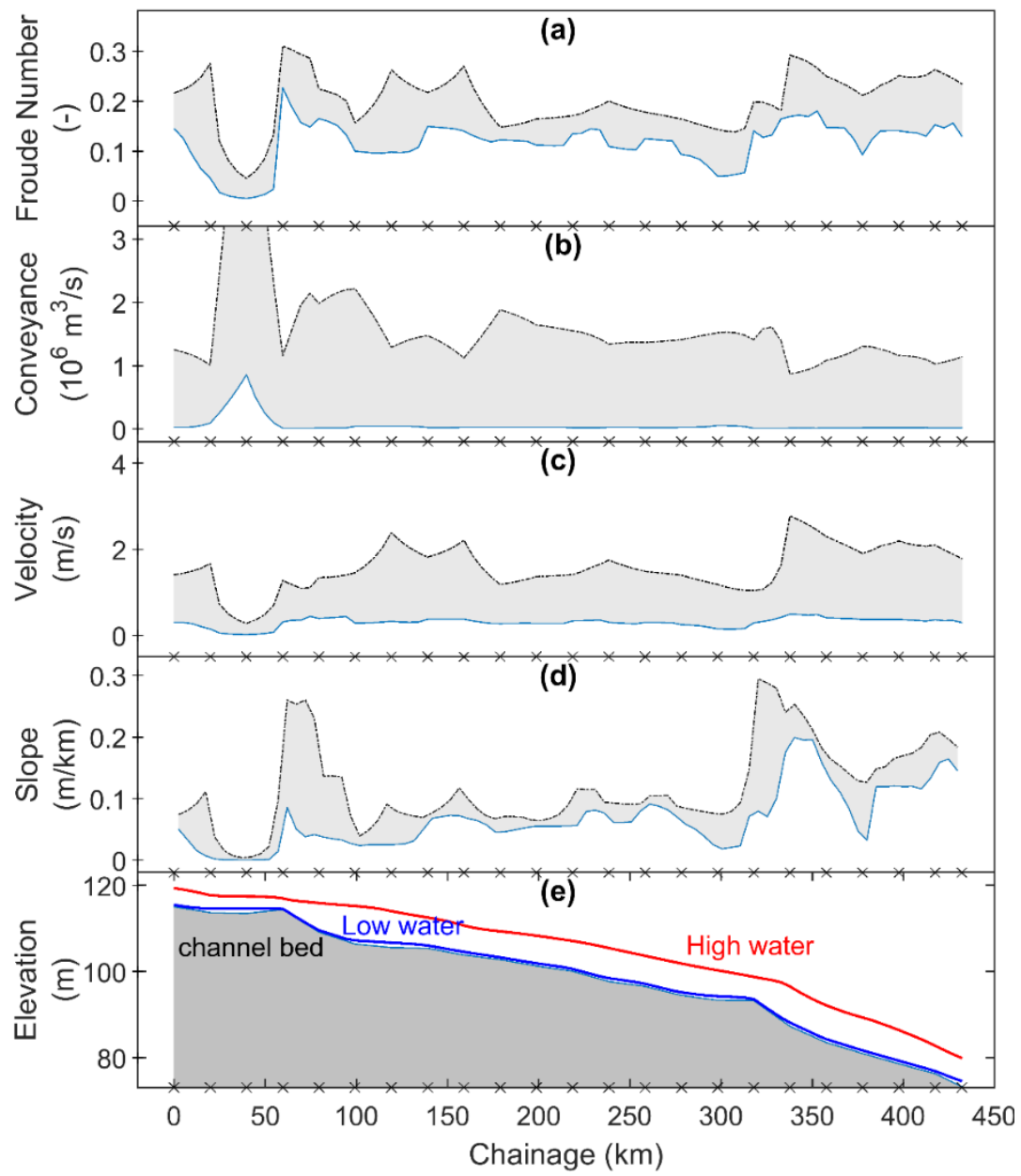

Figure 9. Modelled river hydraulics, including (a) the Froude number, (b) conveyance, (c) mean velocity, (d) water slope, and (d) longitudinal profile of high and low water. Dash-dot black line indicates the maximum value, and blue line indicates the minimum during the simulation period of 2007-2014. The range of each hydraulic factor is shown by shaded area. Black crosses show the locations of cross sections.

\subsubsection{Model evaluation with ground data}

Figures 10 and 11 illustrate the simulated and in-situ WSE at two gauging stations. Overall, the calibration results are fairly good. The average RMSE at the two gauging stations ranges from $0.37 \mathrm{~m}$ to $0.42 \mathrm{~m}$ (Table 5). At Tonghe gauging station, the simulated WSE is correlated fairly 
515 well with the gauge records in terms of NSE value above 0.9 and RMSE below $0.4 \mathrm{~m}$. It should be

516 noted that even though in experiment S2 the model is calibrated during the period of $2007-2010$,

517 the simulated WSE during 2010 - 2014 is comparable to other calibrations (Figure 10). Considering

518 the extreme events, all model calibrations overestimate the flood peak in 2013 and the low flow

519 period in 2012 to some extent.

At Yilan gauging station, the model performance is also good in terms of NSE and RMSE. As shown in Figure 11, the inter-annual fluctuation is well captured by the model. WSE associated with the flood in 2013 is also reproduced with correct timing but smaller magnitude. Nevertheless, WSE associated with extreme droughts (in 2008 and 2012) is overestimated (Figure 11).
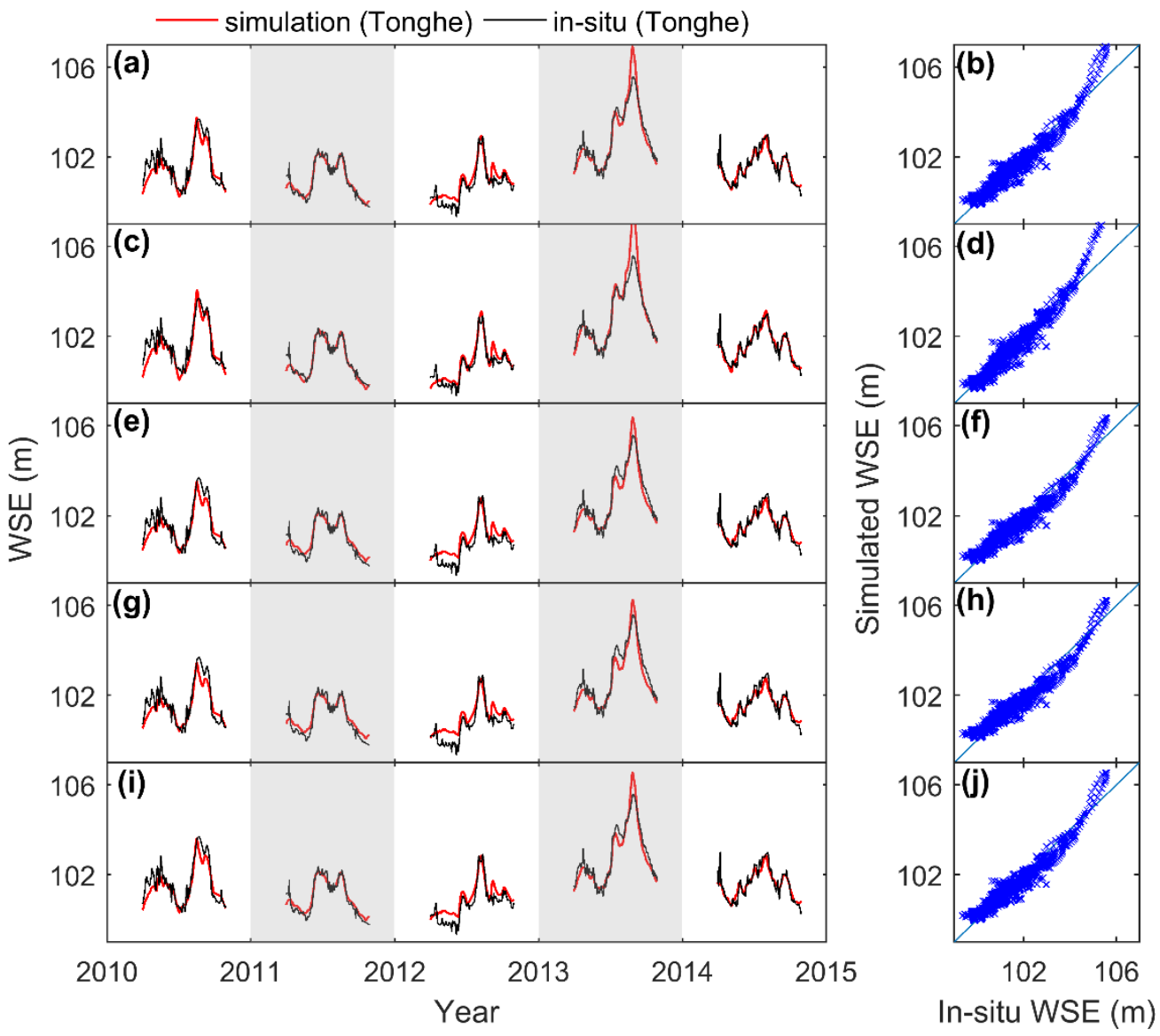

Figure 10. Comparison of WSE at Tonghe gauging station simulated by the calibrated model using (a) and (b) CryoSat-2 during 2010 - 2014, (c) and (d) Envisat during 2007 - 2010, (e) and (f) Jason- 


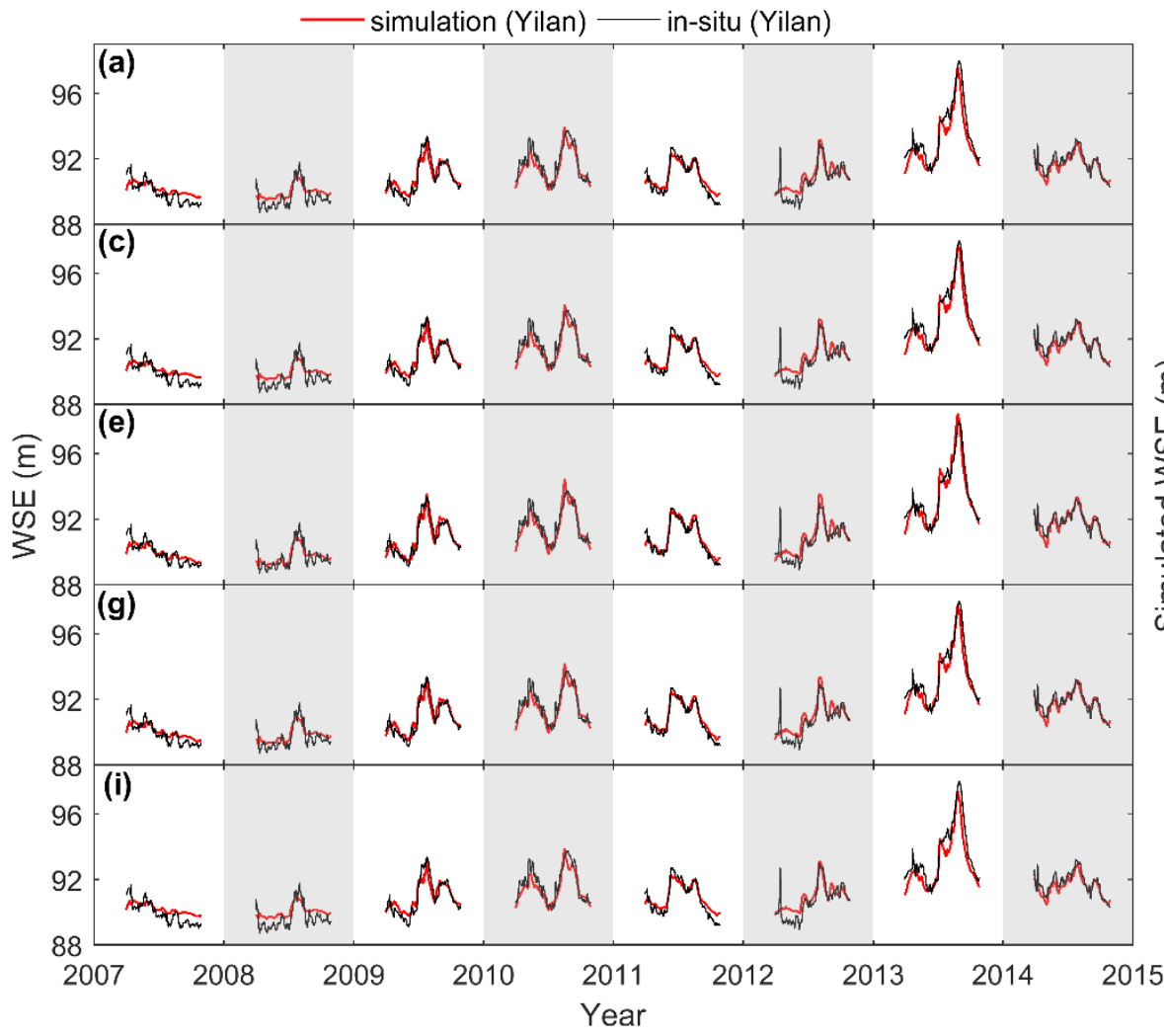

Figure 11. Similar to Figure 10, but at Yilan gauging station during 2007 - 2014.

\section{Discussion}

\subsection{Effect of altimetry sampling pattern}

Higher spatial resolution, i.e. smaller ground inter-track distance, plays a key role in calibrating channel parameters. CryoSat-2, SARAL and Envisat can constrain the variability of both parameters (i.e. $K_{s}$ and $Z_{0}$ ) well, especially the river bed datum $\left(Z_{0}\right)$. As illustrated in Figures 4-6, the uncertainty increases with the number of VSs decreasing. This is clear from the comparison of Jason-1 and Jason-2 although they have similar numbers of observations. Intuitively, it makes sense that higher spatial resolution (geodetic missions) can work better considering these parameters are 
spatially heterogeneous and time-invariant to some extent. In this regard, CryoSat-2 and SARAL far outperform other missions. We argue that the unique spatial sampling pattern of CryoSat-2 and SARAL is valuable for inland hydrology, especially in data-sparse regions, where altimeters with coarse ground track are limited in characterizing heterogeneous parameters. Our results demonstrated that geodetic missions, i.e. CryoSat-2 and SARAL, provide valuable information for mapping river morphological characteristics and calibrating Strickler coefficient. This has also been verified in the extensively monitored Po River (Schneider et al., 2018b). On the other hand, higher temporal resolution does not show a significant improvement in our synthetic experiments. Improvement of data accuracy from a standard deviation of $\sim 40 \mathrm{~cm}$ to $\sim 20 \mathrm{~cm}$ does not proportionally refine model parameters. This is meaningful for future altimetry missions designed for surface water monitoring, such as the Surface Water Ocean Topography (SWOT) mission, which will provide WSE, slope, and top width simultaneously (Biancamaria et al., 2016). We are aware that higher accuracy is still valuable for other studies. An accuracy of $40 \mathrm{~cm}$ is sufficient to support parameter calibration.

Hydraulic resistance is a lumped term, which is expressed in terms of resistance coefficients (e.g. Manning's number and Chezy's number) (Bates et al., 2014). The hydraulic resistance compensates for unrepresented processes. It is a difficult variable to estimate since it depends on many factors that contribute to flow resistance, such as channel geometry, riverine vegetation, materials of river bed, channel sinuosity, etc. For example, in the case of setup S4 (calibration using Jason-2 in section 4.2), 2 VSs are not sufficient to constrain parameter variability along the whole reach. The calibrated $K_{s}$ values are much lower than in the other experiments, but the simulated WSE still matches well the observed one. This is compensated by overestimated datum (Figure 8d). On the contrary, highly spatially distributed altimetry data ease the calibration of spatially variable roughness. For example, CryoSat-2 and Envisat have successfully identified maximum Strickler coefficient $K_{s}$ value at around XS 17 (Figure 7). The upcoming SWOT also faces the same problem, 
i.e. roughness coefficient is needed for many algorithms to retrieve discharge, river depth, etc. (Durand et al., 2016, 2014).

\subsection{Representation of channel geometry}

For many rivers worldwide, the channel bathymetry is not available although it is important for hydrodynamic modeling and operational forecasting. Generally, cross-sectional geometry is either assumed as a specific shape (triangle, rectangle, or trapezoid) or delineated from DEM (globally or regionally datasets). However, in the latter approach, one still needs to extrapolate the submerged portion of the cross section (e.g. Domeneghetti, 2016; Yan et al., 2014). In this study, we tested two shapes, i.e. triangle and rectangle. The results indicate that altimetry data only is not sufficient to constrain the bathymetry, channel shape, and resistance simultaneously. In order to calibrate datum and Strickler coefficient, bank inclination angle or channel width is needed. Compared to the former, channel width can be easily estimated from satellite images. As Neal et al (2015) suggested, that large wide rivers may have effectively rectangular channel geometry, and in such cases, complicated channel geometry (i.e. parabolic), may not add value. The approach presented here can be an option for calibration of datum and roughness jointly in data-scarce regions. Retrieval of bathymetry and cross section from space, especially satellite-based instruments, is still not available to date. There is a strong argument that channel geometry should also be estimated through calibration (Wood et al., 2016).

\subsection{Limitations and assumptions in this calibration approach}

As the synthetic experiments revealed, data accuracy $(20 \mathrm{~cm}$ vs $40 \mathrm{~cm})$ does not have significant effect on calibration but spatial density of data plays a pivotal role in model calibration. It should be noted that here we are focusing on the overall performance along the entire river instead of local performance at specific gauging stations, which can be improved with more accurate observations at a given location. In order to constrain model parameter uncertainty and increase 
identification of parameters, models need to satisfy the behavioral criterion at spatially distributed locations (Schumann et al., 2008). Overall, our approach shows promising results comparing with similar studies. For example, Domeneghetti et al. (2014) calibrated a quasi-2D model in the Po river against Envisat data and found a RMSE around $1 \mathrm{~m}$ although surveyed cross-sections were used.

However, we are aware that 1D parsimonious models have limitations for modeling lower shallow reaches and extreme flood events (overestimated WSE). A simplified geometry does not allow sufficient physical representation of the channel and floodplain, especially for extreme flood events (e.g. the 2013 flood event). This indicates that rectangular cross sections cannot represent the floodplain at Tonghe, and thus the model overestimates the water level (Figure 10). Besides, the number of XS also affects calibration and can introduce uncertainty of the calibrated parameters. This is because altimetry observations are not exactly located at the XSs. When comparing simulated WSE and altimetry-derived WSE, the latter is interpolated to nearby XS. This will introduce uncertainty to some degree. A denser set of XS will reduce this uncertainty and better represent the river morphological characteristics. However, computational cost of the calibration will increase correspondingly. Besides, in this approach, a $L_{2}$ regularization is used to smooth the solution. However, many rivers have specific hydraulic control at certain sections, and therefore robust regularization can be considered.

\section{Concluding remarks}

This study investigated the utility of altimetry-derived water surface elevation (WSE) data for calibrating a hydrodynamic model. Synthetic experiments were first conducted and showed the capability to recover the parameters individually $\left(K_{s}, Z_{0}, \theta, b\right)$ and jointly for some combinations. Specifically, WSE alone is insufficient to constrain the triplets $\left(\left(K_{s}, Z_{0}, \theta\right)\right.$ and $\left.\left(K_{s}, Z_{0}, b\right)\right)$ and doublets $\left(\left(K_{s}, \theta\right)\right.$ and $\left.\left(K_{s}, b\right)\right)$. Different scenarios demonstrated that calibration against high spatial 
612 resolution WSE (i.e. CryoSat-2 and SARAL) performs overwhelmingly better than others. Low

613 spatial resolution data (e.g. Jaon-1/-2) has limited capability to capture variability along the whole

614 river reach even though the temporal resolution is higher. These findings reveal that geodetic

615 altimetry missions with drifting ground track pattern are more skillful than short-repeat missions in

616 constraining spatially distributed parameters of hydrodynamic models. In addition, data accuracy

617 improvement from a standard deviation of $40 \mathrm{~cm}$ to $20 \mathrm{~cm}$ does not proportionally improve

618 parameter identification.

619 Calibrations against real-world observations confirmed the good performance with Cryosat-2

620 data. Envisat achieved a satisfactory result with 10 virtual stations (VSs), whereas combined Jason-

6211 and Jason-2 constrained the parameters to a lesser extent. However, Jason-2 alone could not

622 identify the morphological characteristics with only two VSs even though the simulated WSE was

623 comparable with the other calibrations. This indicates that the traditionally used short-repeat

624 missions have limited ability to constrain parameters although they are favored due to the

625 straightforward way to construct time series. This may have implication for future altimetry

626 missions which are dedicated for hydrological research.

627 Our modeling approach has two notable features. First, it calibrated bathymetry and roughness

628 coefficients jointly. This is promising in the sense of no requirement of bathymetry data, and can

629 be used for other poorly gauged rivers. Second, the modeling approach with distributed altimetry

630 observation (e.g. CryoSat-2 and SARAL) can better constrain spatially distributed parameters.

631 In a general sense, altimeters with dense ground tracks are very useful for calibration of

632 spatially distributed parameters. This case study clearly demonstrates the added value of CryoSat-

6332 and SARAL in supporting hydrodynamic modeling for large-scale and data-scarce rivers.

634 Moreover, this method can be applied to the upcoming SWOT satellite observations, which include

635 water area, height, and slope. 


\section{Acknowledgements}

We would like to thank Raphael Schneider (GEUS) for valuable discussion at early stage. The first author is funded by China Scholarship Council, which is greatly acknowledged. Altimetry data used in this study are available from CNES AVISO+, LEGOS CTOH, and DTU Space, which are acknowledged for making the altimetry data available. Meteorological data can be obtained from the China Meteorological Data Service Center. Hydrological data were obtained from the Hydrological yearbook, which can be obtained by contacting L. Jiang (ljia@env.dtu.dk). We would like to thank the four anonymous reviewers for their helpful comments.

\section{Appendix A Hydrological modeling results}

As described in the main text, hydrological model parameters for 3 catchments (Hulan River, Tangwang River, and Mayi River) were calibrated against discharge using automatic calibration during 2007-2011 and validated during 2012-2014. In the end, optimized parameters from Hulan catchment were then transferred to ambient ungauged catchments. The hydrological simulations are satisfactory when comparing against in-situ records (Figure A1 and Table A1). 

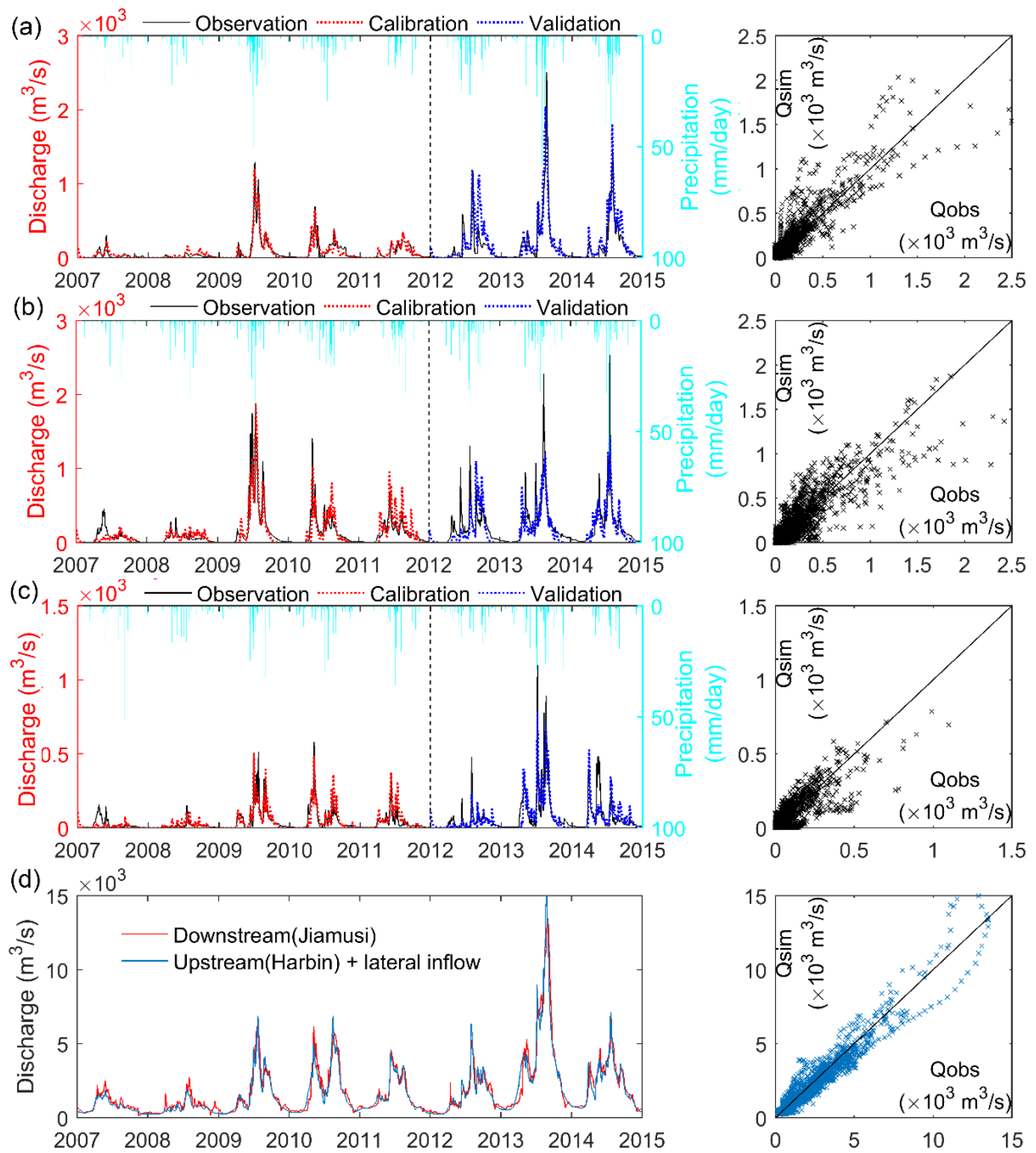

Figure A1 XAJ model simulation performance in (a) Hulan River, (b) Tangwang River, (c) Mayi

Table A1 Parameters used in the XAJ model

\begin{tabular}{|c|c|c|c|}
\hline Symbol & Description (units) & Lower bound & Upper bound \\
\hline \multicolumn{4}{|c|}{ Snowmelt parameters } \\
\hline $\mathrm{TS}$ & Threshold temperature $\left({ }^{\circ} \mathrm{C}\right)$ & -2 & 3 \\
\hline DDF & Degree-day factor $\left(\mathrm{mm} /{ }^{\circ} \mathrm{C} /\right.$ day $)$ & 1 & 6 \\
\hline CFR & Refreezing factor & 0 & 0.3 \\
\hline
\end{tabular}


WHC Water holding capacity

Runoff generation parameters

$\begin{array}{llll}\text { WUM } & \text { Water storage in upper layer (mm) } & 5 & 100 \\ \text { WLM } & \text { Water storage in lower layer (mm) } & 10 & 150 \\ \text { WDM } & \text { Water storage in deep layer (mm) } & 20 & 400 \\ \text { K } & \text { Coefficient of conversion of PET to actual ET } & 0.1 & 1.2 \\ \text { C } & \text { Coefficient of ET in the lower layer } & 0.1 & 0.7 \\ \text { B } & \text { Exponent of the soil water capacity curve } & 0.1 & 0.9 \\ \text { IMP } & \text { Ratio of impervious area to total area (\%) } & 0 & 0.1 \\ \text { Routing parameters } & & \\ \text { SM } & \text { free water capacity (mm) } & 5 & 100 \\ \text { EX } & \text { Exponent of free water capacity curve } & 1.1 & 2 \\ \text { KG } & \text { Outflow coefficient of free water storage to ground } & 0.1 & 0.7 \\ \text { KI } & \text { Outflow coefficient of free water storage to interflow } & 0.1 & 0.7 \\ \text { CG } & \text { Recession constant of groundwater storage } & 0.5 & 0.99 \\ \text { CI } & \text { Recession constant of interflow storage } & 0.01 & 0.99 \\ \text { CS } & \text { Recession constant in the 'lag and route' method } & 0.01 & 0.7 \\ \text { L } & \text { Lag in time (day) } & 0 & 6\end{array}$

Table A2 Calibration and validation results of the hydrological modeling $\left(^{*}\right.$ for the whole

657 catchment, the sum of tributary outflow is compared with the difference between downstream and 658 upstream flow, i.e. Jiamusi and Harbin stations)

\begin{tabular}{llllllll}
\hline \multirow{2}{*}{ River basin } & \multicolumn{3}{c}{ Calibration } & & \multicolumn{3}{c}{ Validation } \\
\cline { 2 - 4 } \cline { 7 - 8 } & NSE & PBIAS & $\mathrm{R}^{2}$ & & & & \\
\hline Hulan river & 0.90 & -0.01 & 0.91 & & 0.74 & 16.23 & 0.78 \\
Tangwang river & 0.80 & -0.43 & 0.81 & & 0.70 & -17.91 & 0.72 \\
Mayi river & 0.72 & -0.18 & 0.74 & & 0.70 & -11.44 & 0.71 \\
whole catchment $^{*}$ & 0.91 & 9.50 & 0.93 & & 0.93 & 2.12 & 0.93 \\
\hline
\end{tabular}

\section{Appendix B Correlation coefficients of parameters}

Figures below show the correlation coefficients of calibrated parameters, which explain the poor performance of model calibrations summarized in Table 4. Clearly, width b and Manning-Strickler coefficient $\mathrm{K}_{\mathrm{s}}$ are strongly negatively correlated in the 3-parameter calibration (Figure B1). Even 
664 when only width $\mathrm{b}$ and Manning-Strickler coefficient $\mathrm{K}_{\mathrm{s}}$ are calibrated, the correlation remains 665 strong and increases in $\mathrm{K}_{\mathrm{s}}$ can be compensated with decreases in width (Figure B2).

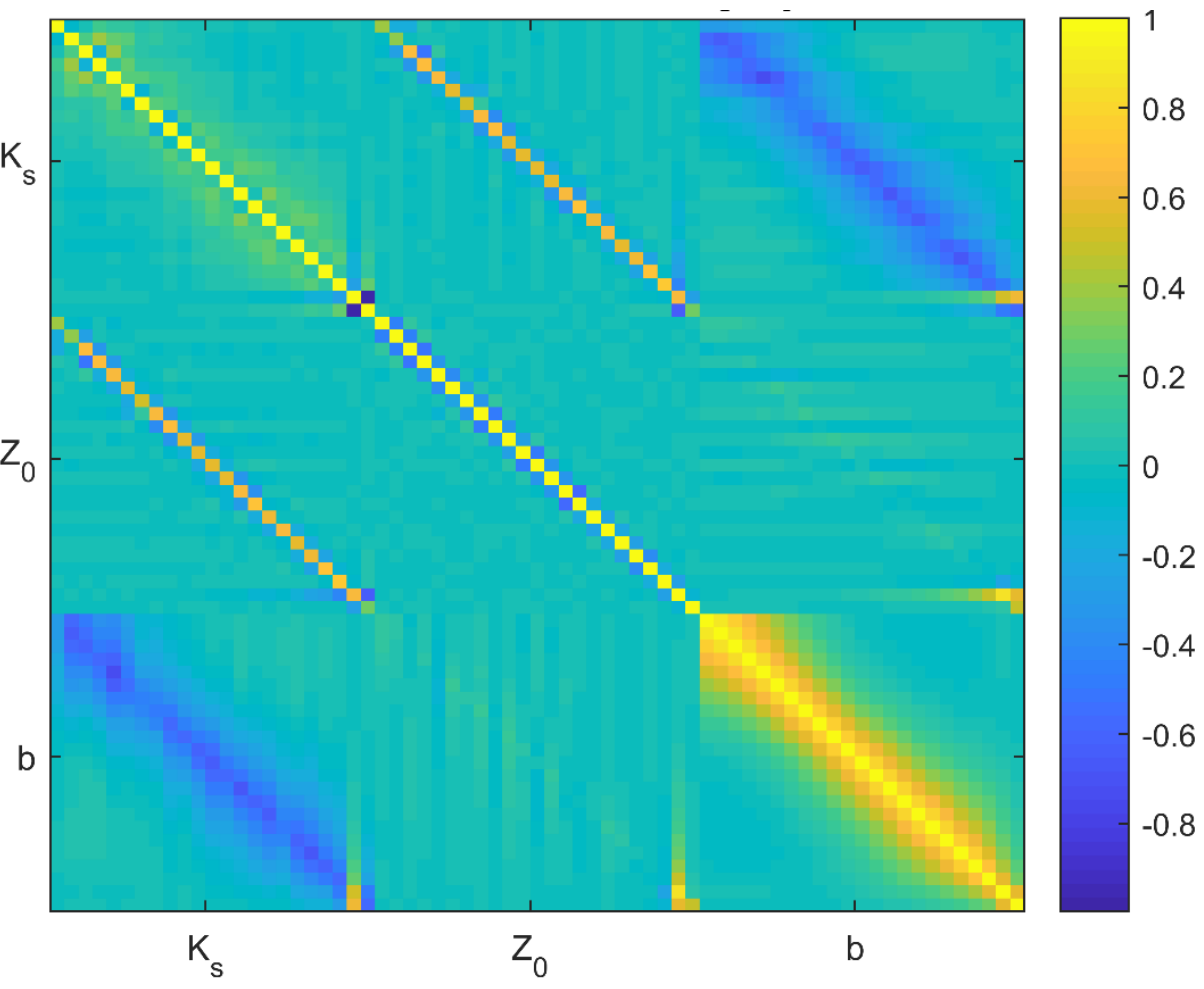

668 Figure B1 Correlation coefficients of 3-parameter calibration, in total 69 parameters calibrated. 


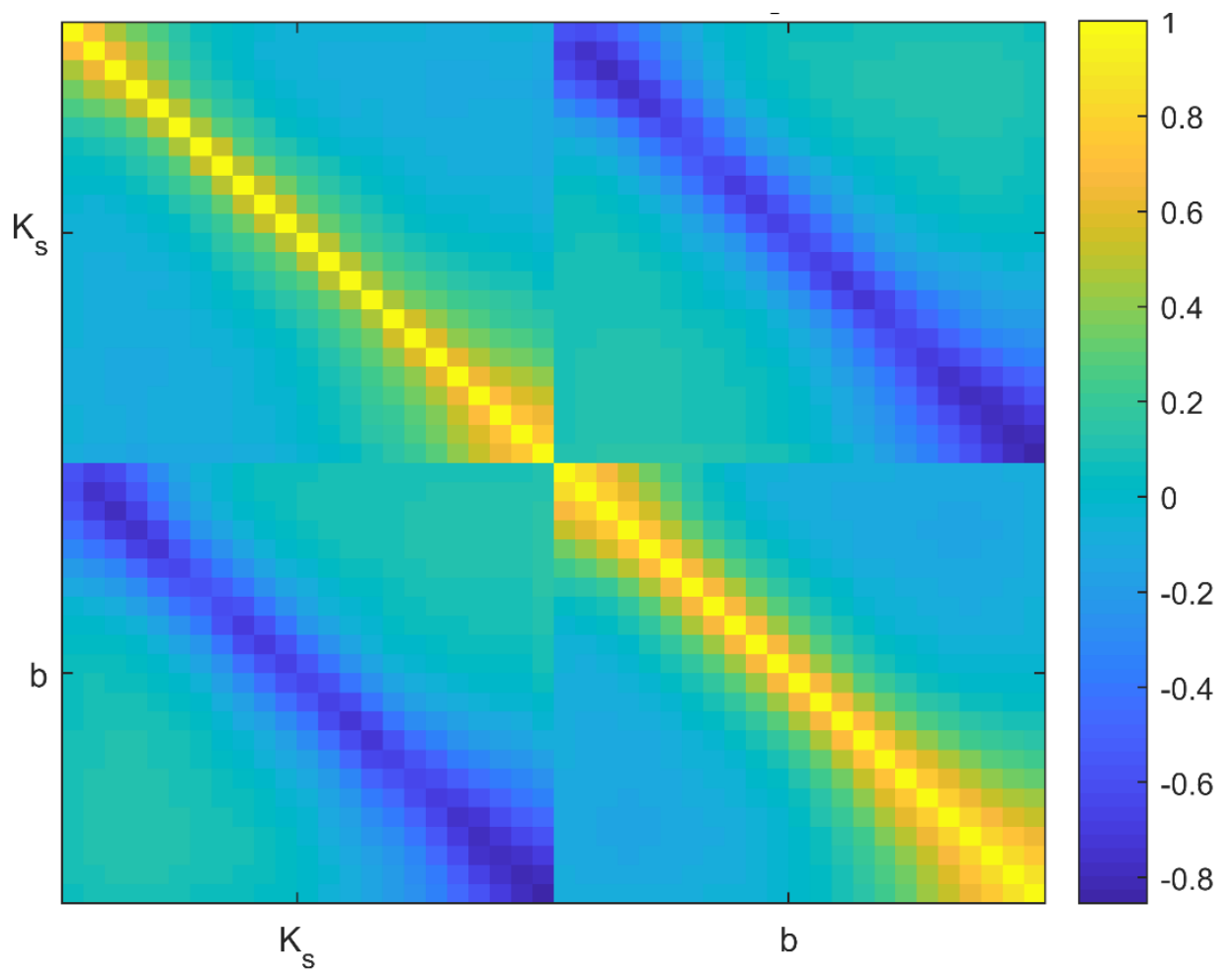

671 Figure B2 Correlation coefficients of 2-parameter calibration, in total 46 parameters calibrated.

672 Appendix C Results of hydrodynamic synthetic experiments

673 Table C1 Summary of calibration performance of synthetic experiments with respect to coverage

674 (perfect value is 95\%), sharpness (smaller is better), and CRPS (smaller is better) using rectangle

675 shape at $95 \%$ confidence interval.

Data source No. of obs. Experiment Coverage (\%)

Sharpness $\quad\left(K_{s} \quad: \operatorname{CRPS}\left(K_{s}: \mathrm{m}^{1 / 3} / \mathrm{s}\right.\right.$

$\left.\left.\mathrm{m}^{1 / 3} / \mathrm{s}, Z_{0}: \mathrm{m}, b: \mathrm{m}\right) \quad Z_{0}: \mathrm{m}, b: \mathrm{m}\right)$

\begin{tabular}{lllll}
\hline & RA1 $\left(K_{s}\right)$ & 82.6 & 6.5 & 1.1 \\
\cline { 2 - 5 } CryoSat-2 & \multirow{2}{*}{$451\left(K_{s}\right)$} & 87.0 & 11.1 & 1.4 \\
\cline { 2 - 5 } & \multirow{2}{*}{$\operatorname{RA} 2\left(Z_{0}\right)$} & 91.3 & 0.39 & 0.07 \\
\cline { 2 - 5 } & $\operatorname{RB} 2\left(Z_{0}\right)$ & 87.0 & 0.65 & 0.11 \\
\cline { 2 - 5 } & $\operatorname{RA} 3(b)$ & 82.6 & 45 & 12.9 \\
\cline { 2 - 5 } & $\operatorname{RB} 3(b)$ & 87.0 & 78 & 18.6 \\
\cline { 2 - 5 } & $\operatorname{RA4}\left(K_{s} \mid Z_{0}\right)$ & $95.7 \mid 95.7$ & $10.4 \mid 0.61$ & $1.2 \mid 0.07$ \\
\cline { 2 - 5 } & $\operatorname{RB} 4\left(K_{s} \mid Z_{0}\right)$ & $95.7 \mid 100$ & $15.6 \mid 1.02$ & $1.8 \mid 0.11$ \\
\cline { 2 - 5 } & $\operatorname{RA6}\left(Z_{0} \mid b\right)$ & $82.6 \mid 87.0$ & $0.64 \mid 144$ & $0.12 \mid 26.4$ \\
\cline { 2 - 5 } & $\operatorname{RB} 6\left(Z_{0} \mid b\right)$ & $100 \mid 91.3$ & $0.98 \mid 210$ & $0.13 \mid 22.3$ \\
\hline
\end{tabular}




\begin{tabular}{|c|c|c|c|c|c|}
\hline \multirow{10}{*}{ Envisat } & \multirow{10}{*}{507} & RA1 $\left(K_{s}\right)$ & 87.0 & 11.4 & 2.0 \\
\hline & & $\mathrm{RB} 1\left(K_{s}\right)$ & 91.3 & 16.5 & 2.6 \\
\hline & & $\overline{\text { RA2 }\left(Z_{0}\right)}$ & 91.3 & 1.09 & 0.15 \\
\hline & & $\mathrm{RB} 2\left(Z_{0}\right)$ & 100 & 1.30 & 0.12 \\
\hline & & RA3 (b) & 65.2 & 78 & 31.0 \\
\hline & & $\overline{\mathrm{RB} 3(b)}$ & 78.0 & 116 & 31.4 \\
\hline & & $\overline{\mathrm{RA}} 4\left(K_{s} \mid Z_{0}\right)$ & \begin{tabular}{l|l|l}
87.0 & 91.3
\end{tabular} & \begin{tabular}{l|l|l|}
16.53 & 1.33
\end{tabular} & \begin{tabular}{l|l|l}
2.8 & 0.31
\end{tabular} \\
\hline & & $\overline{\mathrm{RB}} 4\left(K_{s} \mid Z_{0}\right)$ & \begin{tabular}{l|l|l}
82.6 & 91.3
\end{tabular} & \begin{tabular}{l|l|l}
22.0 & 1.78
\end{tabular} & \begin{tabular}{l|l|l}
3.4 & 0.33
\end{tabular} \\
\hline & & $\overline{\text { RA6 }\left(Z_{0} \mid b\right)}$ & $95.7 \mid 82.6$ & $1.45 \mid 235$ & \begin{tabular}{l|l|l}
0.13 & 43.4
\end{tabular} \\
\hline & & $\overline{\operatorname{RB} 6}\left(Z_{0} \mid b\right)$ & $95.7 \mid 91.3$ & $1.88 \mid 326$ & $0.15 \mid 48.0$ \\
\hline \multirow{10}{*}{ Jason-1 } & \multirow{10}{*}{469} & RA1 $\left(K_{s}\right)$ & 91.3 & 20.8 & 2.8 \\
\hline & & $\mathrm{RB1}\left(K_{s}\right)$ & 91.3 & 22.4 & 2.9 \\
\hline & & RA2 $\left(Z_{0}\right)$ & 95.7 & 2.23 & 0.29 \\
\hline & & $\mathrm{RB} 2\left(Z_{0}\right)$ & 95.7 & 2.47 & 0.21 \\
\hline & & $\overline{\text { RA3 (b) }}$ & 47.8 & 110 & 66.0 \\
\hline & & $\overline{\mathrm{RB} 3(b)}$ & 56.5 & 215 & 61.6 \\
\hline & & $\overline{R A 4}\left(K_{s} \mid Z_{0}\right)$ & $78.3 \mid 87.0$ & $23.7 \mid 2.57$ & \begin{tabular}{l|l|l}
6.0 & 0.71
\end{tabular} \\
\hline & & RB4 $\left(K_{s} \mid Z_{0}\right)$ & \begin{tabular}{l|l|l|}
82.6 & 87.0 \\
\end{tabular} & $29.7 \mid 2.86$ & \begin{tabular}{l|l|l|}
5.4 & 0.50 \\
\end{tabular} \\
\hline & & $\overline{R A 6}\left(Z_{0} \mid b\right)$ & $87.0 \mid 56.5$ & $2.36 \mid 323$ & $0.44 \mid 109.7$ \\
\hline & & RB6 $\left(Z_{0} \mid b\right)$ & \begin{tabular}{l|l|l|}
100 & 91.3 \\
\end{tabular} & $3.15 \mid 449$ & $\begin{array}{l}0.36 \mid 70.2 \\
\end{array}$ \\
\hline \multirow{10}{*}{ Jason-2 } & \multirow{10}{*}{473} & $\operatorname{RA1}\left(K_{s}\right)$ & 65.2 & 22.6 & 7.6 \\
\hline & & $\mathrm{RB} 1\left(K_{s}\right)$ & 60.9 & 26.4 & 13.2 \\
\hline & & $\overline{\mathrm{RA} 2\left(Z_{0}\right)}$ & 91.3 & 3.31 & 0.36 \\
\hline & & $\mathrm{RB} 2\left(Z_{0}\right)$ & 91.3 & 4.27 & 0.62 \\
\hline & & RA3 (b) & 56.5 & 521 & 103.8 \\
\hline & & $\overline{\mathrm{RB}} 3(b)$ & 65.2 & 516 & 93.9 \\
\hline & & RA4 $\left(K_{s} \mid Z_{0}\right)$ & $\begin{array}{l}65.2 \\
\end{array}$ & $23.3 \mid 3.66$ & \begin{tabular}{l|l|l|}
10.1 & 0.86 \\
\end{tabular} \\
\hline & & $\overline{\mathrm{RB}} 4\left(K_{s} \mid Z_{0}\right)$ & \begin{tabular}{l|l|l|}
69.6 & 69.6
\end{tabular} & \begin{tabular}{l|l|l|}
35.0 & 4.33
\end{tabular} & \begin{tabular}{l|l|l|}
8.1 & 0.65
\end{tabular} \\
\hline & & RA6 $\left(Z_{0} \mid b\right)$ & $73.9 \mid 70.0$ & $4.41 \mid 544$ & \begin{tabular}{l|l|l}
1.20 & 129.0 \\
\end{tabular} \\
\hline & & $\overline{\mathrm{RB} 6}\left(Z_{0} \mid b\right)$ & $78.3 \mid 73.9$ & $4.96 \mid 561$ & \begin{tabular}{l|l|l}
1.24 & 108.9
\end{tabular} \\
\hline \multirow{10}{*}{ AltiKa } & \multirow{10}{*}{400} & RA1 $\left(K_{s}\right)$ & 82.6 & 9.0 & 1.5 \\
\hline & & $\overline{\mathrm{RB} 1\left(K_{s}\right)}$ & 100 & 15.1 & 1.5 \\
\hline & & RA2 $\left(Z_{0}\right)$ & 91.3 & 0.36 & 0.06 \\
\hline & & RB2 $\left(Z_{0}\right)$ & 100 & 0.71 & 0.10 \\
\hline & & RA3 (b) & 82.6 & 101 & 18.3 \\
\hline & & $\overline{\mathrm{RB} 3(b)}$ & 65.2 & 126 & 41.0 \\
\hline & & $\overline{\mathrm{RA}} 4\left(K_{s} \mid Z_{0}\right)$ & \begin{tabular}{l|l|l}
87.0 & 95.7
\end{tabular} & $17.6 \mid 0.68$ & $2.4 \mid 0.08$ \\
\hline & & $\mathrm{RB} 4\left(K_{s} \mid Z_{0}\right)$ & $\begin{array}{l}91.3 \mid 95.7 \\
\end{array}$ & $25.3 \mid 1.11$ & $3.8 \mid 0.16$ \\
\hline & & $\overline{\text { RA6 }\left(Z_{0} \mid b\right)}$ & $\begin{array}{l}87.0 \\
91.3\end{array}$ & $\begin{array}{l}0.78 \mid 253 \\
\end{array}$ & $\begin{array}{l}0.12 \mid 46.3 \\
\end{array}$ \\
\hline & & $\overline{R B 6}\left(Z_{0} \mid b\right)$ & $87.0 \mid 82.6$ & $1.09 \mid 390$ & \begin{tabular}{l|l|l|}
0.22 & 69.0 \\
\end{tabular} \\
\hline \multirow{5}{*}{ All missions } & \multirow{5}{*}{2300} & RA1 $\left(K_{s}\right)$ & 91.3 & 4.5 & 0.6 \\
\hline & & $\mathrm{RB} 1\left(K_{s}\right)$ & 87.0 & 7.6 & 1.4 \\
\hline & & $\overline{\text { RA2 }\left(Z_{0}\right)}$ & 100 & 0.22 & 0.03 \\
\hline & & $\mathrm{RB} 2\left(Z_{0}\right)$ & 95.7 & 0.39 & 0.06 \\
\hline & & $\overline{\mathrm{RA} 3(b)}$ & 56.5 & 24 & 10.1 \\
\hline
\end{tabular}




\begin{tabular}{lllll}
\hline $\operatorname{RB} 3(b)$ & 43.5 & 43 & 21.0 \\
\cline { 2 - 5 } $\operatorname{RA} 4\left(K_{s} \mid Z_{0}\right)$ & $95.7 \mid 87.0$ & $6.6 \mid 0.32$ & $0.88 \mid 0.06$ \\
\cline { 2 - 5 } $\operatorname{RB} 4\left(K_{s} \mid Z_{0}\right)$ & $91.3 \mid 95.7$ & $11.2 \mid 0.59$ & $1.71 \mid 0.08$ \\
\hline $\operatorname{RA6}\left(Z_{0} \mid b\right)$ & $73.9 \mid 65.2$ & $0.34 \mid 82$ & $0.12 \mid 38.9$ \\
\cline { 2 - 5 } $\operatorname{RB} 6\left(Z_{0} \mid b\right)$ & $82.6 \mid 73.9$ & $0.55 \mid 124$ & $0.11 \mid 31.0$ \\
\hline
\end{tabular}

676

677

678

679

680

681

682

683

684

685

686

687

688

689

690

691

692

693

694

695

696

697

\section{References}

Andreadis, K.M., Clark, E.A., Lettenmaier, D.P., Alsdorf, D.E., 2007. Prospects for river discharge and depth estimation through assimilation of swath-altimetry into a raster-based hydrodynamics model. Geophys. Res. Lett. 34, L10403. doi:10.1029/2007GL029721

Bates, P.D., Pappenberger, F., Romanowicz, R.J., 2014. Uncertainty in Flood Inundation Modelling, in: Applied Uncertainty Analysis for Flood Risk Management. IMPERIAL COLLEGE PRESS, pp. 232-269. doi:10.1142/9781848162716_0010

Beven, K., Binley, A., 1992. The future of distributed models: Model calibration and uncertainty prediction. Hydrol. Process. 6, 279-298. doi:10.1002/hyp.3360060305

Biancamaria, S., Bates, P.D., Boone, A., Mognard, N.M., 2009. Large-scale coupled hydrologic and hydraulic modelling of the $\mathrm{Ob}$ river in Siberia. J. Hydrol. 379, 136-150. doi:10.1016/j.jhydrol.2009.09.054

Biancamaria, S., Hossain, F., Lettenmaier, D.P., 2011. Forecasting transboundary river water elevations from space. Geophys. Res. Lett. 38, 1-5. doi:10.1029/2011GL047290

Biancamaria, S., Lettenmaier, D.P., Pavelsky, T.M., 2016. The SWOT Mission and Its Capabilities for Land Hydrology. Surv. Geophys. 37, 307-337. doi:10.1007/s10712-015-9346-y

Birkinshaw, S.J., O’Donnell, G.M., Moore, P., Kilsby, C.G., Fowler, H.J., Berry, P.A.M., 2010. Using satellite altimetry data to augment flow estimation techniques on the Mekong River. Hydrol. Process. 24, 3811-3825. doi:10.1002/hyp.7811

Blair, P., Buytaert, W., 2016. Socio-hydrological modelling: A review asking “why, what and how?” 

Hydrol. Earth Syst. Sci. 20, 443-478. doi:10.5194/hess-20-443-2016

Bonnefond, P., Verron, J., Aublanc, J., Babu, K., Bergé-Nguyen, M., Cancet, M., Chaudhary, A., Crétaux, J.-F., Frappart, F., Haines, B., Laurain, O., Ollivier, A., Poisson, J.-C., Prandi, P., Sharma, R., Thibaut, P., Watson, C., 2018. The Benefits of the Ka-Band as Evidenced from the SARAL/AltiKa Altimetric Mission: Quality Assessment and Unique Characteristics of AltiKa Data. Remote Sens. 10, 83. doi:10.3390/rs10010083

Chow, V. Te, 1959. Open channel hydraulics. McGraw-Hill Book Company, Inc, New York.

DHI, 2017. MIKE HYDRO River - User Guide. DHI, Copenhagen.

Domeneghetti, A., 2016. On the use of SRTM and altimetry data for flood modeling in data-sparse regions. Water Resour. Res. 52, 2901-2918. doi:10.1002/2015WR017967

Domeneghetti, A., Castellarin, A., Tarpanelli, A., Moramarco, T., 2015. Investigating the uncertainty of satellite altimetry products for hydrodynamic modelling. Hydrol. Process. 29, 4908-4918. doi:10.1002/hyp.10507

Domeneghetti, A., Tarpanelli, A., Brocca, L., Barbetta, S., Moramarco, T., Castellarin, A., Brath, A., 2014. The use of remote sensing-derived water surface data for hydraulic model calibration. Remote Sens. Environ. 149, 130-141. doi:10.1016/j.rse.2014.04.007

Duan, Q., Sorooshian, S., Gupta, V., 1992. Effective and efficient global optimization for conceptual rainfall-runoff models. Water Resour. Res. 28, 1015-1031. doi:10.1029/91WR02985

Durand, M., Gleason, C.J., Garambois, P.A., Bjerklie, D., Smith, L.C., Roux, H., Rodriguez, E., Bates, P.D., Pavelsky, T.M., Monnier, J., Chen, X., Di Baldassarre, G., Fiset, J.-M., Flipo, N., Frasson, R.P. d. M., Fulton, J., Goutal, N., Hossain, F., Humphries, E., Minear, J.T., Mukolwe, M.M., Neal, J.C., Ricci, S., Sanders, B.F., Schumann, G., Schubert, J.E., Vilmin, L., 2016. An intercomparison of remote sensing river discharge estimation algorithms from measurements of river height, width, and slope. Water Resour. Res. 52, 4527-4549. doi:10.1002/2015WR018434 
Durand, M., Neal, J., Rodríguez, E., Andreadis, K.M., Smith, L.C., Yoon, Y., 2014. Estimating reach-averaged discharge for the River Severn from measurements of river water surface elevation and slope. J. Hydrol. 511, 92-104. doi:10.1016/j.jhydrol.2013.12.050

Eckhardt, K., Fohrer, N., Frede, H.G., 2005. Automatic model calibration. Hydrol. Process. 19, 651-658. doi:10.1002/hyp.5613

Finsterle, S., Kowalsky, M.B., 2011. A truncated Levenberg-Marquardt algorithm for the calibration of highly parameterized nonlinear models. Comput. Geosci. 37, 731-738. doi:10.1016/j.cageo.2010.11.005

Frappart, F., Calmant, S., Cauhopé, M., Seyler, F., Cazenave, A., 2006. Preliminary results of ENVISAT RA-2-derived water levels validation over the Amazon basin. Remote Sens. Environ. 100, 252-264. doi:10.1016/j.rse.2005.10.027

Frasson, R.P. de M., Wei, R., Durand, M., Minear, J.T., Domeneghetti, A., Schumann, G., Williams, B.A., Rodriguez, E., Picamilh, C., Lion, C., Pavelsky, T., Garambois, P.-A., 2017. Automated River Reach Definition Strategies: Applications for the Surface Water and Ocean Topography Mission. Water Resour. Res. 53, 8164-8186. doi:10.1002/2017WR020887

Getirana, A.C. V., Boone, A., Yamazaki, D., Mognard, N., 2013. Automatic parameterization of a flow routing scheme driven by radar altimetry data: Evaluation in the Amazon basin. Water Resour. Res. 49, 614-629. doi:10.1002/wrcr.20077

Gneiting, T., Raftery, A.E., Westveld, A.H., Goldman, T., 2005. Calibrated Probabilistic Forecasting Using Ensemble Model Output Statistics and Minimum CRPS Estimation. Mon. Weather Rev. 133, 1098-1118. doi:10.1175/MWR2904.1

Gupta, H. V., Kling, H., Yilmaz, K.K., Martinez, G.F., 2009. Decomposition of the mean squared error and NSE performance criteria: Implications for improving hydrological modelling. J. Hydrol. 377, 80-91. doi:10.1016/j.jhydrol.2009.08.003

Hostache, R., Matgen, P., Schumann, G., Puech, C., Hoffmann, L., Pfister, L., 2009. Water Level Estimation and Reduction of Hydraulic Model Calibration Uncertainties Using Satellite SAR 
Images of Floods. IEEE Trans. Geosci. Remote Sens. 47, 431-441. doi:10.1109/TGRS.2008.2008718

Jain, M., Andersen, O.B., Dall, J., Stenseng, L., 2015. Sea surface height determination in the Arctic using Cryosat-2 SAR data from primary peak empirical retrackers. Adv. Sp. Res. 55, 40-50. doi:10.1016/j.asr.2014.09.006

Jiang, L., Nielsen, K., Andersen, O.B., Bauer-Gottwein, P., 2017a. CryoSat-2 radar altimetry for monitoring China's freshwater resources. Remote Sens. Environ. 200, 125-139. doi:10.1016/j.rse.2017.08.015

Jiang, L., Schneider, R., Andersen, O.B., Bauer-Gottwein, P., 2017b. CryoSat-2 Altimetry Applications over Rivers and Lakes. Water 9, 211. doi:10.3390/w9030211

Lehner, B., Grill, G., 2013. Global river hydrography and network routing: baseline data and new approaches to study the world's large river systems. Hydrol. Process. 27, 2171-2186. doi:10.1002/hyp.9740

Lettenmaier, D.P., Alsdorf, D., Dozier, J., Huffman, G.J., Pan, M., Wood, E.F., 2015. Inroads of remote sensing into hydrologic science during the WRR era. Water Resour. Res. 51, 73097342. doi:10.1002/2015WR017616

Liu, G., Schwartz, F.W., Tseng, K.-H., Shum, C.K., 2015. Discharge and water-depth estimates for ungauged rivers: Combining hydrologic, hydraulic, and inverse modeling with stage and water-area measurements from satellites. Water Resour. Res. 51, 6017-6035. doi:10.1002/2015WR016971

Liu, J., Chen, X., Zhang, J., Flury, M., 2009. Coupling the Xinanjiang model to a kinematic flow model based on digital drainage networks for flood forecasting. Hydrol. Process. 23, 13371348. doi:10.1002/hyp.7255

Madsen, H., Lawrence, D., Lang, M., Martinkova, M., Kjeldsen, T.R., 2014. Review of trend analysis and climate change projections of extreme precipitation and floods in Europe. J. Hydrol. 519, 3634-3650. doi:10.1016/j.jhydrol.2014.11.003 
Mann, M.E., Rahmstorf, S., Kornhuber, K., Steinman, B.A., Miller, S.K., Coumou, D., 2017. Influence of Anthropogenic Climate Change on Planetary Wave Resonance and Extreme Weather Events. Sci. Rep. 7. doi:10.1038/srep45242

Marquardt, D.W., 1963. An Algorithm for Least-Squares Estimation of Nonlinear Parameters. J. Soc. Ind. Appl. Math. 11, 431-441. doi:10.1137/0111030

McMahon, T.A., Peel, M.C., Lowe, L., Srikanthan, R., McVicar, T.R., 2013. Estimating actual, potential, reference crop and pan evaporation using standard meteorological data: A pragmatic synthesis. Hydrol. Earth Syst. Sci. 17, 1331-1363. doi:10.5194/hess-17-1331-2013

Michailovsky, C.I., McEnnis, S., Berry, P.A.M., Smith, R., Bauer-Gottwein, P., 2012. River monitoring from satellite radar altimetry in the Zambezi River basin. Hydrol. Earth Syst. Sci. 16, 2181-2192. doi:10.5194/hess-16-2181-2012

Milzow, C., Krogh, P.E., Bauer-Gottwein, P., 2011. Combining satellite radar altimetry, SAR surface soil moisture and GRACE total storage changes for hydrological model calibration in a large poorly gauged catchment. Hydrol. Earth Syst. Sci. 15, 1729-1743. doi:10.5194/hess$15-1729-2011$

MWR, 2014. China Water Statistical Yearbook. China Water Power Press, Beijing.

Neal, J.C., Odoni, N.A., Trigg, M.A., Freer, J.E., Garcia-pintado, J., Mason, D.C., Wood, M., Bates, P.D., 2015. Efficient incorporation of channel cross-section geometry uncertainty into regional and global scale flood inundation models. J. Hydrol. 529, 169-183. doi:10.1016/j.jhydrol.2015.07.026

Oubanas, H., Gejadze, I., Malaterre, P.-O., Mercier, F., 2018a. River discharge estimation from synthetic SWOT-type observations using variational data assimilation and the full SaintVenant hydraulic model. J. Hydrol. 559, 638-647. doi:10.1016/j.jhydrol.2018.02.004

Oubanas, H., Gejadze, I., Malaterre, P. - O., Durand, M., Wei, R., Frasson, R.P.M., Domeneghetti, A., 2018b. Discharge estimation in ungauged basins through variational data assimilation: the 
potential of the SWOT mission. Water Resour. Res. 54, 2405-2423. doi:10.1002/2017WR021735

Pavlis, N.K., Holmes, S.A., Kenyon, S.C., Factor, J.K., 2012. The development and evaluation of the Earth Gravitational Model 2008 (EGM2008). J. Geophys. Res. Solid Earth 117, n/a-n/a. doi:10.1029/2011JB008916

Pereverzyev, S.S., Pinnau, R., Siedow, N., 2006. Regularized fixed-point iterations for non-linear inverse problems. Inverse Probl. 22, 1-22. doi:10.1088/0266-5611/22/1/001

Schneider, R., Godiksen, P.N., Villadsen, H., Madsen, H., Bauer-Gottwein, P., 2017. Application of CryoSat-2 altimetry data for river analysis and modelling. Hydrol. Earth Syst. Sci. 21, 751764. doi:10.5194/hess-21-751-2017

Schneider, R., Ridler, M.E., Godiksen, P.N., Madsen, H., Bauer-Gottwein, P., 2018a. A data assimilation system combining CryoSat-2 data and hydrodynamic river models. J. Hydrol. 557, 197-210. doi:10.1016/j.jhydrol.2017.11.052

Schneider, R., Tarpanelli, A., Nielsen, K., Madsen, H., Bauer-Gottwein, P., 2018b. Evaluation of multi-mode CryoSat-2 altimetry data over the Po River against in situ data and a hydrodynamic model. Adv. Water Resour. 112, 17-26. doi:10.1016/j.advwatres.2017.11.027 Schumann, G., Bates, P.D., Horritt, M.S., Matgen, P., Pappenberger, F., 2009. Progress in integration of remote sensing-derived flood extent and stage data and hydraulic models. Rev. Geophys. 47, RG4001. doi:10.1029/2008RG000274

Schumann, G., Cutler, M., Black, A., Matgen, P., Pfister, L., Hoffmann, L., Pappenberger, F., 2008. Evaluating uncertain flood inundation predictions with uncertain remotely sensed water stages. Int. J. River Basin Manag. 6, 187-199. doi:10.1080/15715124.2008.9635347

Siddique-E-Akbor, A.H.M., Hossain, F., Lee, H., Shum, C.K., 2011. Inter-comparison study of water level estimates derived from hydrodynamic-hydrologic model and satellite altimetry for a complex deltaic environment. Remote Sens. Environ. 115, 1522-1531. doi:10.1016/j.rse.2011.02.011 
Songliao River Conservancy Commission, 2015. Water resources bulletin of Songhua \& Liao River. Changchun, China.

Songliao River Conservancy Commission, 2004. The Songhua River. Changchun, China.

Su, C.-H., Peterson, T.J., Costelloe, J.F., Western, A.W., 2016. A synthetic study to evaluate the utility of hydrological signatures for calibrating a base flow separation filter. Water Resour. Res. 52, 6526-6540. doi:10.1002/2015WR018177

Wanders, N., Bierkens, M.F.P., de Jong, S.M., de Roo, A., Karssenberg, D., 2014. The benefits of using remotely sensed soil moisture in parameter identification of large-scale hydrological models. Water Resour. Res. 50, 6874-6891. doi:10.1002/2013WR014639

Wang, Q.J., 1991. The Genetic Algorithm and Its Application to Calibrating Conceptual RainfallRunoff Models. Water Resour. Res. 27, 2467-2471. doi:10.1029/91WR01305

Wood, M., Hostache, R., Neal, J., Wagener, T., Giustarini, L., Chini, M., Corato, G., Matgen, P., Bates, P., 2016. Calibration of channel depth and friction parameters in the LISFLOOD-FP hydraulic model using medium-resolution SAR data and identifiability techniques. Hydrol. Earth Syst. Sci. 20, 4983-4997. doi:10.5194/hess-20-4983-2016

Yan, K., Tarpanelli, A., Balint, G., Moramarco, T., Baldassarre, G., 2014. Exploring the Potential of SRTM Topography and Radar Altimetry to Support Flood Propagation Modeling: Danube Case Study. J. Hydrol. Eng. 20, 4014048. doi:10.1061/(ASCE)HE.1943-5584.0001018

Yoon, Y., Durand, M., Merry, C.J., Clark, E.A., Andreadis, K.M., Alsdorf, D.E., 2012. Estimating river bathymetry from data assimilation of synthetic SWOT measurements. J. Hydrol. 464465, 363-375. doi:10.1016/j.jhydrol.2012.07.028

Zhang, D., Zhang, L., Guan, Y., Chen, X., Chen, X., 2012. Sensitivity analysis of Xinanjiang rainfall-runoff model parameters: a case study in Lianghui, Zhejiang province, China. Hydrol. Res. 43, 123. doi:10.2166/nh.2011.131

Zhao, R.-J., 1992. The Xinanjiang model applied in China. J. Hydrol. 135, 371-381. doi:10.1016/0022-1694(92)90096-E 
